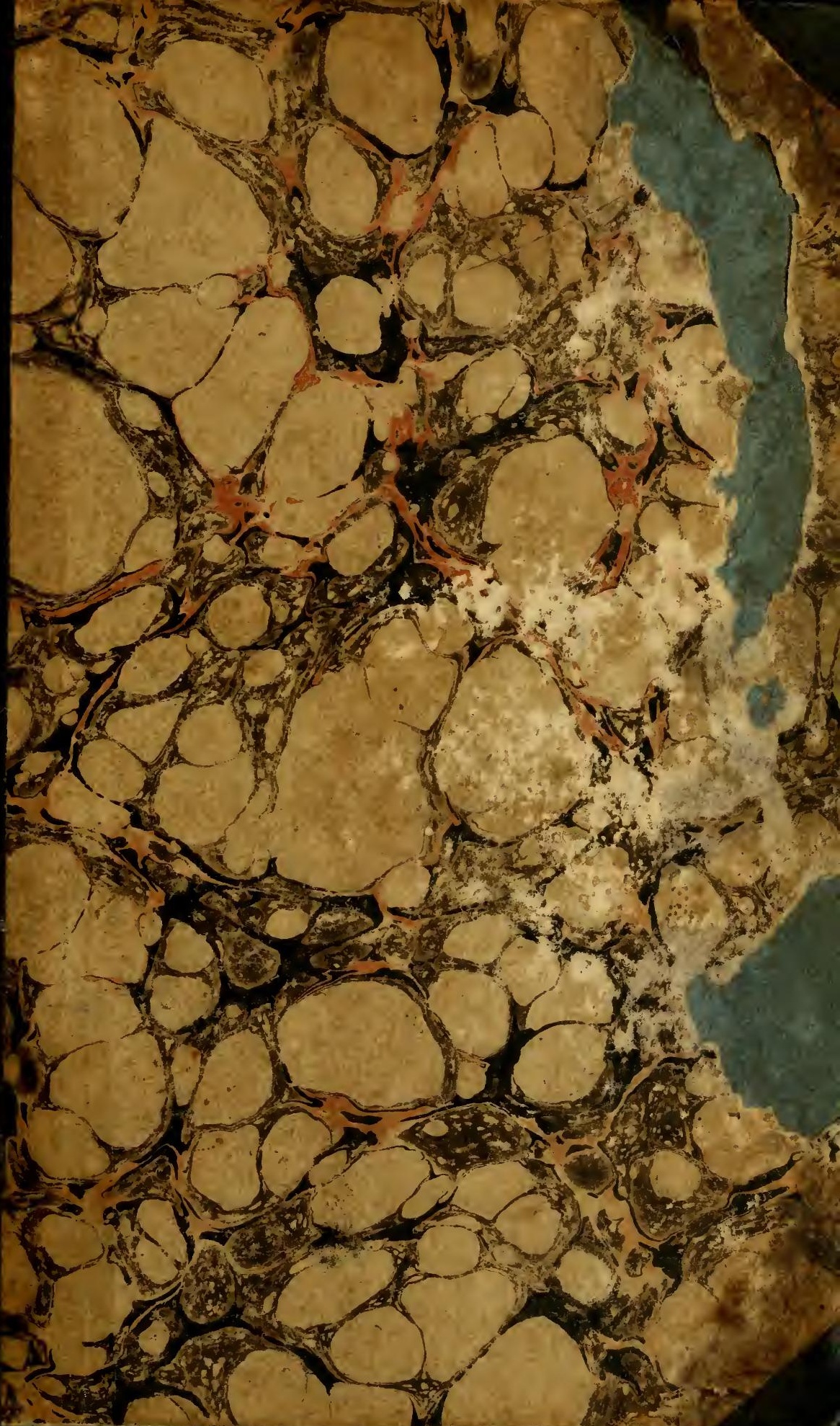




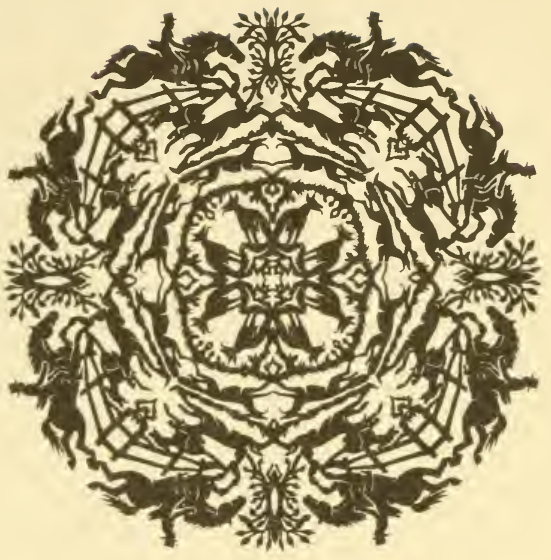

JOHN A.SEAVERNS 
Tobro Thomas stiom EAS Sumplér, 


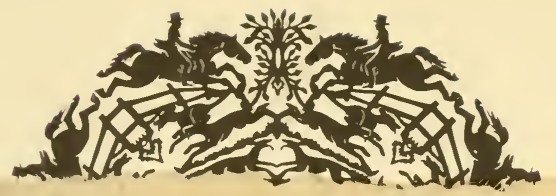


Webster Family Library of Veterinary Medicine Cummings School of Veterinary Medicine at Tufts University nno Whectron Pond 



\title{
VETERINARY PATHOLOGY:
}

$$
\text { or, }
$$

A TREATISE ON THE CAUSE AND PROCRESS OF

\section{THE DISEASES OF THE HORSE,}

Together with the most approved Methods

\section{OF PREVENTION AND CURE.}

TO WHICH ARE ADDED,

SHORT OBSERVATIONS ON

Bleeding, Firing, Roweling, Fomentations, and Poustices,

\author{
AND AN \\ A P P E N D I X; \\ OR, \\ VETERINARY DISPENSATORY: \\ CONTAINING
}

THE MOST APPROVED PRESCRIPTIONS FOR THE DIFFERENT DISEASES OF THE HORSE.

The whrle intended as a GUIDE and COMPANION to

THE GENTLEMAN, VETERINARIAN, AND FARRIER,

\section{SECOND EDITION.}

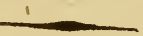

\section{By WILLIAM R RDING,}

VETERINARY SURGEON TÓ THE 18TH LIGHT DRAGOON8.

\section{Tamian:}

PRINTED FOR J. MAWMAN, 22 POULTRY.

$$
1804 \text {. }
$$

By T. Gillet, Salifury-Square. 



\section{EDWARD COLEMAN, EsQ.}

WROFESSOR OF THE VETERINARY COLIEGE.

\section{SIR,}

I HUMBLY presume to place this short Treatise under your kind protection, from a confidence that you will view all its errors with the eye of a father. I am the more led to this, from the consideration, that the Veterinary Art was in its infancy, and wanted a person of abilities to display its native beauty and utility; when, fortunately. for these Isles, you was placed in a situation in which your talents became of eminent service to Mankind, in furnishing means for the preservation of so valuable an animal as the Horse. I am,

$$
\text { SiR, }
$$

Your most devoted

And very humble servant,

$$
\text { W. RYDING。 }
$$





\section{$P R E F A C E$.}

\section{W}

HILST the attention of the learned has been employed in investigating the anatomy and diseases of the foot, and making improvements in shoeing, little progrefs has been made in the other parts of the Veterinary Art, although it must appear obvious to every reader, and to the world at large, that a description of the cause and progrefs of the diseases to which that useful and valuable animal the Horse is subject; at the same time, pointing out such methods of practice as are sanctioned only by reason, and confirmed by experience, must be a very important acquisition to the public.

THE difficulty of composing a work of this kind, must appear to every one, when it is considered that I have only the symptoms of a dumb irrational animal to afsist me, in distinguishing one disease 
from another; whilst the physician and surgeor have not only the knowledge of the ancients, the more recent improvements of the moderns, but also the information of rational beings, gifted with the advantage of speech.

In looking into most of the works which have appeared on Farriery, I find that more attention has been paid to criticisin and scurrility, than improvement: and though in different hands the subject las been drefsed in different language; yet on examining their contents, I find the authors to be merely plagiurists of each other.

As the Veterinarian has only symptoms, by which he can be led to distinguish the disease, I have been very particular on that important part; haring made it my principal study in a very extensive practice : and I hatter myself, that the practitioner will, in gencral, find $n \mathrm{y}$ statements accurate.

IN this work I have been as concise and brief as polsible, by leaving out all matter foreign to the subject, and continng myself to the statement of facts; yet at the sane time omitting nothing in my power which may tend to instruct and improve; 
* for which purpose, I have fiequently inserted cases, where I thought they would illustrate the subject.

IN the plan of this work, I have first endeavoured to describe the disease; secondly, to point out its cause. I next proceed to describe the symptoms, beginning with the most simple, tracing them in their progrefs to the most inveterate stages; and, lastly, to direct such medicines, diet, \&c. as I have ever found most effectual for their removal.

IN the prescriptions, I have adopted the most efficacious medicines; and have likewise rendered them lefs complex, without depriving them of any part which I conceive might have been added with advantage. This, to those gentlemen who choose to depend on their own practice, will be a valuable acquisition, as well as to the Veterinarian and Farrier. For amongst such a number of recipes presented to us by different authors, all warranted infallible antidotes, we find it extremely difficult on which to fix ; and, when the choice is made, find ourselves often disappointed, though some of them are said to have cost the publisher upwards of five hundred pounds. 
IN colds, diseases of the luugs, and in many other complaints, a profusion of expectorant medicines are generally amongst the prescriptions directed by most authors for their removal; but it is a well-known truth, that the Horse is unable either to romit or expectorate: and I can safely say, from experience, that such medicines tend more to opprefs and increase, than to remove the symptoms or disease.

I LIKEWISE wish to show my marked disapprobation of the use of strong purgatives; by which too frequently more injury is done to the animal in a few hours, than can be repaired in as many weeks. They certainly are very useful in some cases, but never should be trusted in an unexperienced hand.

THE purges prescribed in this work, will be found to be conposed principally of aloes, sometimes united with calonel. Jalap, gamboge, and scammony, I have not recommended; as their action on the Horse is not only extremely doubtful, but often injurious; and as aloes and calonel are found to answer every desirable intention.

Srnce I wrote on the treatment of Infammation of the Lungs, in which I advised the practitioner to use gentle purges, joined with oscasional mild 
diuretics, I have seen upwards of fifty cases where that kind of treatment has been adopted, and proved so succefsful, as to exceed my most.sanguine expectations; but previous to giving the medicine, the patient should lose from three to four quarts of blood, which may be repeated occasionally. This method of practice cannot be too much recommended, as it is a well-known fact, that inflammation of the lungs destroys annually more young horses, than all the other diseases to which the Horse is incident.

WHEN mercurials are given, it will be necefsary to keep the Horse from being exposed to cold as much as pofsible; as mercurial medicines, by their tendency to pafs off by the surface, make the body more irritable and susceptible of injury from sudpen changes of temperature.

IN speaking of diuretics, it will be found that I have rejected the fixed alkalis, which only have a tendency to injure the stomach and intestines, and have confined myself entirely to the use of turpentines: On them we can always depend. The form, as it now stands, is simple, though not lefs efficacious: for by only increasing or diminishing the quantity, we can produce, to a certainty, a greater or lefser action of the kidneys. 
I WIsH strongly to recommend the use of antimony, as an alterative in colds, long-continued discharges of matter from the nostrils, and in all cutaneous diseases: and I am convinced, that its effects are rendered more permanent, when occasionally joined with mild diuretics. Py its tendency to promote the secretions, and by removing obstructions in the most minute vefsels of the body, it will be found to strengthen the appetite, improve condition, and preserve the horse from a number of discases.

I HAVE purposely omitted the disease called Glanders, as I have at present little to offer on that subject; but hope to be able to say something on that disease at a future period; as I am collecting every informution respecting its cause, progrefs, and cure, which observation and experiment can furnish.

I HAVE not entered into an inquiry or description of the different soris of food ustally given to horses; as I conceire it to be a subject so unirersally known, as not to require any information in my power to girc.

In this Work I have declined treating on the discases of the Foot, and the proper method 
of shoeing, as those important subjects have been thought worthy the attention of the present learned and judicious Profefsor of the Ve-terinary College; whose knowledge in those branches of the Veterinary Art has, by his late Publication, put the world in pofsefsion of every improvement of which the subject is capable.

I HAVE now gone orer the outlines of this Work, and leave the candid reader to form his orrn opinion. Happy for me, if my labours may be in some degree of service to the Public, by preserving for them the life of so valuable and useful ar animal as the Horse. 



\section{CONTENTS}

\section{Page}

INTRODUCTION , . . , , . . 17

On the actual Cautery . . . . . . 19

On Roweling . . . . . . . . . . 19

On Blistering . . . • . . . . . 21

On Fomentations and Poultices . . . . . 22

On the Teething of Horses . . . . . 22

Of Inflammation in general . . . . . 23

Treatment of Inflammation . . . . 31

\section{On Woundin General.}

Of Incised Wounds . . . . . . . 36

On the suppurative Procefs in Wounds . . 38

On Punctured Wounds . . . . . . 41

Wounds of the Joints . . . . . . 42

Contused and lacerated Wounds . . . . 45

On Ulcers . . . . . . . . . . 47

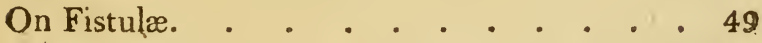

Of Hæmorrhage, or Bleeding in general . . 51 
Page

On Sprains • • . • • • . • . 55

On Bone Spavin, Splints, and Curbs . . 57 Splints and Curbs . . . . . . . 61 Recent Colds, or Catarrh . . . . . 61 On Fever . . . . . . . . . 65 Inflammation of the Lungs . . . . . 69 Broken Wind . . . . . . . . . 73

Diseases of the Liver. Jaundice . . . . . . . . . 75

Diseases of the Kidneys.

Supprefsion of Urine . . . . • . . 79 Diabetis . . . . . . . . 81 Diseases of the Bladder . . . . . . 82

Diseases of the Intestines.

Of the Cholic or Gripes . . . . . . 86 Diarrhœa or Loosenefs . . . . . . 88 Slecpy and Mad Staggers . . . . . . 92 Farcy . . . . . . . . . . 94 Grease . . . . . . . . . . 99 Mange . . . . . . . . . . 103 Strangles . . . . . . . . . 105 Hidle-bound, Bots, and Worms . . . 108 
Diseases of the Eyes . . . . . . 114 Of the Membrane Nictatans . . . . 118 On Roaring . . . . . . . . . 119 Broken Knees . . . . . . . . . 119 Mallenders and Sallenders . . . . 120 On depraved Appetite . . . . . . 121 The Distemper . . . . . . . 121

\section{APPENDIX.}

No. 1. Mild purging Ball . . . . . 127

No. 2. Mercurial purging Ball • . . 127

No. 3. Diuretic, or Urine Balls . . . 128

No. 4. Stomachic Balls . . . . . . 128

No. 5. Improved Cordial Balls . . . . 129

No. 6. Mild Camphor, or Fever Balls . . 129

No. 7. Fever Powder . . . . . . 130

No. 8. Mild alterative Porders for promoting Condition . . . . 130

No. 9. Mild Drink for Pains of the Bowels,

Loosenefs, or Difficulty in Staling . 131

No. 10. Eye-Water, for Film or Specks . . 131

No. 11. Mixture for Strains, Swellings, Sc. 131

No. 12. Mixture for old Sores . . . . 132

No. 13. Blister Ointment . . . . . 132

No. 14. Strong Blister Ointment for Bone Spavin, Splints, \&c. . . . 132 
No. 15. Digestive Ointment for common Sores 133 No. 16. Powder for removing Fungus, or Proud Flesh . . . . . 133

No. 17. Oinument for Mange . . . 133 No. 13. Common Clyster . . . . . 134 No. 19. Linseed Decoction . . . . 134 No. 20. Opordeldoc . . . . . . . 134 No. 21. Volatile Opodeldoc . . . . 135 
YETERINARY PATHOLOGY.

\section{INTRODUCTION.}

DF all the quadruped animals, the Horse seems the most beautiful, as well as most useful; the noble largenefs of his form, the glofsy smoothnefs of his skin, the graceful ease of his motions, and the exact symmetry of his shape, have taught us to regard him as the first and the most perfect of the brute creation; and yet, what is very extraordinary, if we examine him internally, his structure will be found more different from that of man, than any other quadruped whatsover: for as the ape approaches us the nearest in internal conformation, so the horse appears to be the most remote.

THE horse is very much injured by blows upor the ears or stifle, and also by strong purges. His 
diseases are, in general, more violent than those of man, and they terminate much sooner. He recovers his natural strength, from a state of great debility, very rapidly. His stomach, though assisted by the great length of his intestines, seem only to extract a tincture from his food, and appear to be incompetent to complete digestion.

His constitution is naturally adapted to heat, seldom arriving at any great degree of perfection in cold climates. He is more subject to disease in England than on the Continent, or in warmer countries; which is principally owing to his being exposed to the frequent sudden changes of tem r perature to which this island is exposed.

AFTER the above observations, which we think may be useful to the practitioner, we shall endeavour to make some short remarks on the effect and usefulnefs of Firing, Roweling, Blistering, sic. and then proceed to the cause, progrefs, and treatment of the different diseases to which the Horse is liable. 


\section{On the actual Cautery.}

IN using the cautery, we have very much the advantage over those who practise on the human subject; for we have little to apprehend from inflammation or fever; as in many cases it would be impofsible to remove the disease without its afsistance: and however witers may attempt to censure its use, by affected feelings of humanity, we venture to afsert, that to its potent effects the most inveterate ulcers, strains, spavins, and ligamentary lamenefs owe their cure, when every other application has been found to fail. The pait it causes is comparatively small, its effects immediate and powerful; and we can afsure the reacier, that, when prudently used, it is not attended with the least danger. In applying it to the legs, care should be raken not to let the iron burn too deep, so as to divide the skin, and the lines should be drawn perpendicular, about half an inch from each other:

\section{On Roweling.}

WHAT may be understood by roweling, is only 2 simple incised wound, (not penetrating the muscle) made in any depending part of the body; which, by its lips or edges being kept open, by 
the introduction of extraneous substance and stimulating medicines, (spirits of turpentine, ) a constant supuration is promoted. This discharge is evidently from the whole system; and if the rowels are numerous, and long continued, produce great debility.

IT will appear from what has been said, that roweling may be of service when matter is suspected to be forming in some of the important parts of life; such as the lungs. Roweling, by lowering the system, and promoting absorption, may carry the matter into the circulation, and be thrown off by the common emunctories, or may determine its action to a lefs important part. Roweling, by its tendency to promote absorption, will be found serviceable in swelled legs, or where a discharge bas been long continued from an ulcer; which, if suddenly stopped, may do great injury, without an artificial drain is procured in some other part of the body. In such cases, before the rorrels are removed, a course of mild alterative medicines should be adopted.

VE have seen modern authors advising rawels in the chest for inflammation of the feet; but by what means rowels in the chest, or any other part of the body, can remove the diseases of the feet, wo 
are at a lofs to account. This, we think, is one of the many errors which crept into practice, when people were ignorant of the nature of the foot; and has been handed from father to son, each taking it as a fact, and inserting it in his works, without giving the subject a proper degree of attention.

\section{On Blistering.}

BLISTERING is another powerful stimulant, and is excellent in strains, windgalls, spavins, and sometimes in inveterate grease; it will likewise be found of great advantage applied to the throat, and under the jaw, in strangles, colds, coughs, \&ic. and much superior to rowels, when applied over the chest in inflammation of the lungs. The best blister is that which is composed of fresh powdered cantharides and oil, or purified hog's lard. The common proportion is, one part cantharides to two of oil or lard; and it is attended with this advantage, that it never destrors the roots of the hair, which is too frequently the case with those which are composed of sublimate euphorbium and of oil of origanum, which often leave a blemish that can never be removed. By adding or diminishing the quantity of the cantharides, we can make it more or lefs powerful, if required. 


\section{On Fomentutions and Poultices.}

\section{FOMENTATIONS and POULTICES are very} useful applications for removing inflammation, promoting suppuration, \&c. The first need to be simple warm water only, as it will answer every purpose of its application, if persisted in for a due length of time; and where poultices are required, the common bran, boiled in water one hour, and used when sufficiently cold, or with an addition of linseed meal, will be found the best. The poultice should be changed when it is become cold, and repeated as often as found necefsary.

\section{On the Teething of Fiorses.}

AS it is a well-known fact, that most animals are subject to violent diseases during the time of teething, so too much care cannot be taken of horses at this time: for it is observed, that until the age of five years, when the teeth become complete, they are subject to the most dangerous diseases; such as violent colds, strangles, inflammation of the lungrs. Young horses being naturally more irritable than old horses at this time, the irritability is much increased, the circulation from exertion is nuch more rapid, and the glands more liable to become obstructed. To prevers: 
these disagreeable consequences, they should frequently take three or four drams of aloes made into a ball, with the addition of a little ginger and soap; their diet should be rather low, avoiding giving them at all times large quantities of corn, and sudden violent cxercise; they should be kept as much as pofsible in a moderate degree of temperature, and never be permitted to remain any length of time in a hot stable.

\section{Of Infiammation in general.}

BY well understanding Inflammation, we shall be led to the knowledge both of the cure and causes of many diseases. The afsemblage of symptoms of local inflammation are; first, an increased action of the heart and arteries, rednefs, (this, though it evidently takes place, is not perceived in the horse, owing to the thicknefs of the skin, and covering of hair,) tension, swelling, accompanied with a painful sensation, tending to acute pain; this depending more or lefs on the degree of sensibility and irritability of the parts. This pain is increased by stretching or prefsure; a distinct pulsation is also felt. These symptoms are always present in a greater or lefser degree, and are sometimes carried to so great an extent, as to inpede or hinder the functions of parts. 
WHEN infammation is general, together with the increased action of the heart and arteries, there is an hard, full, strong, and fiequent pulse: Blocd that is drawn from a vein, remains longer fluid; but when become firm, its surface is covered with a whitish appearance, which is commonly termed buf:. The patient's tongue is dry and white; there is also greut thirst, accompanied with lofs of appetite.

THE causes of local inflammation are violent blows, falls, sprains, various kinds of wounds, and substances entering those wounds. It may also be derived fiom a general affection, as fever of the lungs; but the most frequent cause of inflammation in the horse, is from sudden change of temperature, or it may arise in a part without any apparent cause. In inflammation, the vefsels of the part are enlarged, and are generally increased in number : in consequence of the enlarged size of the arteries, more blood is sent to the part; and if the part be glandular, the secretion of the gland is increased, the sensibility is increased, and parts that were before insensible are now, in this unnatural state, become irritable and painful.

'Crus action is most probably in tliesmall vefsels at first; but the larger ones are certainly concerned 
in the action, as the inflanmation increases. The pain depends much on the structure of the part; for where it is confined by horn, as in the foot, or under fascix; it is much more acute. The swelling is produced by something thrown out by the exhalant arteries into the inflamed part, and which is the coagulable lymph and serum. The lymph coagulates, and the serum transudes into the surrounding cellular membrane, so that where the cellular membrane is loose, the swelling will be greater, as it also will in a depending part.

INFLAMMATION may terminate in resolution, adhesion, suppuration, and gangrene; sometimes producing a disease worse than inflammation, and at other times preventing a disease. When the increase of action, pain, swelling, and tenson gradually subside, without any evacuation of matter, this is called terminating by resolution; but this cannot take place without the parts are entire, and the irritating cause removed. It is necefsary to the keeping up of infiammation, that the cause should be increased, otherwise the parts, becoming accustomed to the cause, will return to their natural functions. This fact may be rery well illustrated by the friction of an horse's collar. This, before the parts are accustomed to it, will produce such irritation as, even to lay the parts raw; but, after 
a short time, unlels the degree of friction be increas. ed, there will not be the least irritation produced. It may terminate by bleeding; but this is seldom the case with the horse, except it be procured by the lancet. It may terminate by an enlarged secretion; for instance, in infiammation of the membrane of the nose, we often find a larger secretion of mucus, and sometimes of a matter similar to pus. It may also be resolved by the smaller vefsels throwing out a large quantity of the thinner part of the blood. If this should happen in the thorax, it may produce a dropsy of the thorax; if in the cavity of the abdomen; a dropsy of the abdomen. We should therefore always endeavour to prevent this kind of termination.

Terminating by adhesion; is the union of parts, without the medium of granulations. This procefs may take place in the internal parts, from two inflamed surfaces coming into contact, or from the velsels of one inflamed surface throwing out coagulable ljn ph, which becoming solid, forms a medium into which vefsels shoot; so that the vefsels of one surface communicate with those of the other. This procefs may either constitute, prevent, or cure a disease. It may constitute disease, by forming an unnatural adhesion; may prevent it, by stopping the progrefs of inflammation; and 
may cure, by uniting divided parts. Inflammation, when it takes place internally, and when it happens in a vital part, most commonly terminates by adhesion.

WHEN adhesions have taken place in any of the internal viscera, they will be in time considerably elongated, adapting themselves to the motions of the parts: For instance, we happened, in March, 1799 , to be at the dog-kennel belonging to his Royal Highnefs the Prince of Wales at Brighton, at the time a horse was killeil for the hounds; when, upon the thorax being opened, we found the left lobe of the lungs adhering to the plura, covering a circle of more than three inches diameter. Upon inquiry, we found that the animal, when living, had shown no symptoms to indicate such an adhesion, having regularly performed his daily labour, his extreme age being the only cause of his destruction *.

When inflammation takes place in cellular parts, the lymph is thrown out; which coagulating immediately, forms a kind of boundary, by plugging

* These internal adhesions seem to give little pain, and may prevent the whole cavity of the thorax or abdomers from going into suppuration. " 
up the different cells. By its uniting property; it seems to prevent the surrounding parts from going into inflammation; and wher suppuration takes place, it prevents the matter from getting into the cellular membrane, by plugging up the mouths of the cells, and by becoming solid. This is illustrated by every large abscefs, where we can always discover a kind of boundary, formed by the lymph limiting the size of the abscefs in a certain degree. This lymph, if the inflammation has not run very high, will soon be absorbed; but if there has been a considerable quantity thrown out, it may remain for a length of time before the tumor it forms is subsided.

$\mathrm{BY}$ increased action of inflamed parts, (exceeding that which produces arthesion) pus is formed. It has been said, that extravasated blood has been the cause of producing pus, or by fermentation taking place; but the most probable way of pus being formed, seems to be the following; viz. the vefsels of the part taking on a peculiar action at this time, in consequence of the inflammation, hare a power of secreting a peculiar fiuid.

ThE Grease is an illustration of this opinion: for we find, that if this disease has continued a length of time, and the inflammation has run very 
bigh, the refsels of the fetlock, or pastern joint, take on the action of secreting horny substance, similar to those of the feet.

IT seems neceisary to the formation of pus, that the action of the vefsels be increased beyond that producing adhesion; but still this increase of action should go no further than a certain degree : for we find, that if this action is carried to too great a degree, suppuration will not take place. It seems to be the intention of nature, in forming pus, to throw off some extraneous matter; pulsation is felt, and the pain is more vioient in the part during the formation of pus. The constitutional symptoms are likewise increased, the pulse is hard and more frequent, and the fever augmented; the cellular part into which pus is thrown being taken up by the absorbents, or being broken down by the fluid which is thrown out, becomes mixed with it. The coagulable lymph sometimes remaining for a considerable time after the matter has been. evacuated, before it is absorbed, hence that induration and thicknefs of parts from which pus has been evacuated. After pus is completely formed, the pain and swelling subside, as do also the constitutional symptons.

THE period at which suppuration takes place 
varies much, but generally, in a common abscefs, about the fourth day. This, however, takes place sooner in a young horse than in an old one; it also takes place sooner in parts that are not glandular, and particularly in those parts that are near the source of circulation. Some parts do not admit of suppuration; for instance, a tendon: but if the inflammation runs to a great height, gangrene and mortification may ensue. It sometimes happens, after puss is formed, that neither the local nor constitutional symptoms abate; this may be owing either to the great irritability of the constitution, or to the matter being confined by bone or fascia. Pus is generally evacuated by an external outlet, or it may be taken up by the absorbents.

Pus is, when examined from a healthy sore or abscefs, an unctuous, whitish, opake, equal fluid, perfectly inodorous, much resembling cream, and of a sweetish mild taste. When examined by the microscope, its colour, like that of the blood, seems to depend upon a number of small round globules, nearly resembling those observed in milk, and which appear to swim in a fluid. The thicknefs of pus seems to depend upon the number of glopules; greater quantities being always found in thick laudable pus. Its specific gravity is equal to about that of blood. It sinks very readily in water" 
and will not unite with it in the cold of the atmosphere. Heat does not coagulate it, but it evaporates to drynefs. The difference between pus and mucus is, that mucus is ropy, and has no globules, appearing through the microscope to be flaky; whereas pus in its healthy state, has no appearance of being ropy. The fluid in which the globules swim, differs from serum, in having no power of coagulating by the addition of sal ammoniac; from chyle, by its globules being larger, and not coagulating by heat; and from milk, by its not coagulating by the addition of rennet. In its healthy state, it is perfectly inactive, but is capable of alteration by disease ; so much so, that it is often is very acrimonious, and will corrode the parts with which it is in contact.

\section{Treatmezint of Inflammation.}

THE first consideration, is the cause of inflammation; the second is, whether it ought to be cured; thirdly, in what state we should attempt the cure; and, fourthly, by what means.

The consideration of these circumstances is highly important; and if we are able to discover the first, it will answer the two next. The necessity of attending to these circumstauces, may be 
seen from the effects of inflammation. In some cases it is salutary; and should we attempt to re. move it, we may destroy the patient. Those inflammations which produce critical abscefs, should not be resolved. When seated in the lungs, or in the liver, after a disease, or in any other vital part, suppuration should be prevented from taking place by every pofsible means.

WHEN it arises for the purpose of removing any extraneous body, it should be brought to suppuration; though, if the symptoms should run very high, they should be lefsened. It often arises from no apparent cause; here it must be left, with regard to its treatment, to the surgeon's judgment.

WHERE inflammation arises from external vio. lence, and where nature does not seem to have any particular intention in view, we should endeavour to bring it to resolution: this may be attempted during the first four or five days; but this depends on circunstances. The first thing is the knowledge of the irritation: for if we can remove the cause of diseased action, the parts will return to their proper tone. If produced by prefsure or friction, the cause producing it must be remored. 
If the natural secretion of a part is become acrimonious by inflammation, so as to excoriate any part, that part must be defended by oils, mucilages, kc. Oil of olires, almonds, spermaceti, linseed, and mucilages of gum-arabic and quinces may be applied; the latter, if in a fresh state, is a very good application.

If motion increases the inflammation, the parts should be kept at rest as much as pofsible. If it is increased by cold, the patient should be kept in a mild temperature. If the stimulus arises from the distention of parts, a continuation of fomentations, such as the constant application of warm water may be beneficial. Pure exprefsed oils are also found to have relaxant effects.

PAIN in general is only a consequence of inflammation, though sometimes it may be a means of continuing it, in proportion as the sensibility in. creases. Poultices of the simplest kind should be used, such as bran and warm water, or linseed meal; the latter of these is preferable, from its not being so liable to become lumpy, and from not becoming sour. Opium and other applications, such as preparations of lead, are often used. When the parts are very irritable, these may allay pain. If opiurn is used externally, it ought to be 
administered very freely; for if it is applied it small quantities, it will sometimes increase the irritability. Lead not only tends to lefsen the action of the parts, but also to lefsen the powers, by producing permanent weaknefs. Cold is a great seuatire, but if long continued, may produce morification. Other applications; as decoctions of bryony, wormwood, acids, vinegar, the vitriolic and muriatic acid diluted, may be used with good effect.

Resolution may be afsisted, by increasing the circulation in a neighbouring part, as by using raf'els, blisters, \&c.

WIIEN the infiammation is extensive, and has effected a vital part, and where the powers are very great, bleeding will have very desirable effects. In this ease, the blood should be evacuated as quickly as pofible, through a large orifice; two quarts taken away in this manner, will prore more effectual than four quarts taken gradually. Bleeding should not be continued from the appearance of the blood being sizy, for this appearance may take place from weaknets.

WHEN infammation has affected a vital part, we must be regulated in bleeding by the state of 
the pulse. It should be small at first in quantity; but should the pulse rise after it, as is sometimes the case, we need not be afraid of repeating it. Where the pulse is also hard, strong, and frequent, and the powers are great, bleeding largely must take place, and vice versa.

WHERE the urine is in small quantities, and of an high colour, we may venture to bleed. We should attend to the patient's diet; warm mashes of bran, sometimes mixed with a few oats, and a little sweet hay, or grafs, will be found the best food.

MEDICINEs producing nausea may be given, as tending to lefsen the living powers; such as tartar emetic, antimonial powder, nitre, acids, warm water, \&c. will diminish the irritability.

GLIsters and purgings are also a means of lessening inflammation; but, in irritable habits, these should be used with caution : of these the aloetics and mercurials are preferable.

WHEN the whole of the constitution sympathizes, the same means must be pursued. When suppu. ration takes place, it may also be diminished by the same means. 


\section{On Wounds in Generat。}

\section{Of Incised Wounds.}

ALL wounds may be divided into Incised, Contused, and Functured; each of these require different modes of treatment. We shall first take into consideration the Incised, as being the most simple.

When the wound is first rnade, and the cutting finstrument withdrawn, a retraction of the parts, and bleeding, follow. If it is only through the skin and cellular membrane, the degree of retraction will depend on the tension of the skin; if nuscular fibres are divided acrofs, the retraction will be considerably greater than if the wound was made in the course of them. The bleeding will depend on the vascularity of the part, and whether the round is made acrofs the muscles, or in a longitudinal direction, as in the first case the large, but in the latter, probably only the smaller vefsels will be cut.

AFTER the blood has flowed some time, the blecding by degrees ceases, partly from the con'traction, and partly from the lymph plugging up the mouths of the divided versels; but in the saal 
arteries, bleeding most probably ceases from their contractile power. The pain depends on the sensibility and tension of the skin, which, of all parts, is most sensible of pain.

THERE is scarcely any case of fresh incised wounds, where we should not attempt union by the first intention $\%$. Though there is often great difficulty in bringing and keeping wounds in contact, which is owing to our not being able to preyent the horse's motion, and principally from the panniculus carnosus muscle moving the skin. By this method, wounds which formerly were known not to be cured under five or six weeks, are pow cured in as many days. We should alnays endeavour to remove the coagulated blood, before we attempt bringing the parts in contact, either by a sponge, or warm water; care being taken not to have the water too hot, lest we should bring on a return of the bleeding.

Sometrimes we are unable to clear the whole congulated blood away; and, should we persevere too much in our attempts, may do great harm, by increasing the irritation. A small quantity remain-

* Union by the first intention, is only the simple operation of uniting the edges of the wound either by the needle and thread, by bandages, or sticking plaster. 
ing, should not deter us from attempting an im. mediate union. The surfaces should, if pofsible, be brought into contact betore the oozing out of the lymph, and before a great degree of infamma. tion has taken place, otherwise suppuration may ensue.

For bringing and keeping wounds in contact, various kinds of sutures have been recommended; but at present only two are in general use, viz. the interrupted and twisted suture. In deep extensive wounds, the first of these is preferable ; but in those wounds where much motion is used, the latter is of more service. A double thread, with the crooked needle, will, in general, be all that is required.

\section{On the Suppurative Procefs in Wounds.}

IN some cases, instead of union taking place by the first intention, the pain and tension increasing? we must, in this case, remove the ligatures, \&c. and wait the event of suppuration.

Sometimes union may be impeded by extraneous substances in the wound; but, after their removal, it may be effected. These substances, if small, may be remored by a sponge and water; 
but if they are large, we must attempt their remoral either by the finger or instruments, and should a great chance of union appear, the wound may even be enlarged. If the extraneous body is too large to be extracted by the wound, but at the same time can be perceived in a different part, and nearly approaching to the skin, a cointe: opening may be made, provided the adjacent parts are not liable to injury from the division of large blood-refsels or nerves. If, however, there is a difficulty in extracting these extraneons bodies, attended with a chance of hæmorrhage, we must give up the idea, and wait for suppuration.

DRY lint, or fine tow, spread with Venice turpentine, are, in general, the best drefsings we can apply; but, in some ulcers, lint may irritate the parts to a great degree, particularly where it is stuffed in; a mode of drefsing very injurious, it being only necefsary for it to be laid lightly on the surface. But as no matter is secreted on the edges of the sore, and of course the lint may be liable to adhere to them, an emollient ointment may be spread over it. It is an erroneous idea, that prefsure in the beginning will afsist in forming granulations; but, when they are formed, prefsure may then be of service. 
Natural retraction disposes the part to sup. puration, and healthy granulation.

In large and deep wounds, and where inflammation runs high, poultices will be found service. able. One disadvantage attends the use of them, which is the difficulty of applying them in various parts of the body: where they cannot conveniently be applied, fomentations may be used; and we should consider, on taking off the dreisings, whether they seem to agree with the sore, or whether it may not be proper to change them.

IN drefsing wounds, we should be careful not to expose their surfaces too long to the air. We should also be careful in wiping off the pus, part of which may be suffered to remain, from having no noxious quality, and from appearing to protect the parts. The general health of the horse should also be attended to; the bowels should be kept open; and, if any great degree of irritability is apparent, bleeding may be used, and opium may be given. The parts should also, as much as pofsible, be kept at rest. 


\section{On Punctured Wounds.}

PUNCTURED WOUNDS are much more difficult of cure than incised wounds, from the many different parts liable to be wounded, as skin, cellular membrane, muscles, nerves, tendon, \&c.; the external opening being small, if suppuration takes pluce, it is almost impofsible for the matter to be evacuated; hence fistulous ulcers arise.

If any extraneous body is lodged in the wound, and there is great difficulty in getting at it without dilating the wound, or if matter should work its way to any of the surrounding parts, and we are not likely to do mischief, from the division of nerves, or large-blood-vefsels, we may cut down upon it, and extract it ; but ir danger is to be apprehended from the division of either of the above, we must wait for suppuration.

If there should be matter lodged under the fascia, we should open it directly, and reduce it to a fiesh incised wound.

If a puncture should be superficial ; that is, if it should run under the skin and cellular membrane only, it will then be best to lay it open to its full extent. 
If it should penetrate through a muscle, it may be better to palis a seton through it, than to expose it to the air.

IF it becomes fistulous, it must be treated like any other fistulous sore.

\section{Founds of the Joints.}

WOUNDS, if not penetrating the carity of the joint, should be treated like any other simple wound, keeping the inflanmation as much under as pofsible.

If penetrating the cavity, they cannot be better elucidated, than by describing a recent dangerous caie, which terminated succefsfully.

"A Asout the latter end of May, 1799, a horse belonging to the Hampshire Fencible Light Dragoons, Colonel Thomas Cooper Everitt commander, unfortunately got one of his fore-feet over the chain in the stall, and being of a very irritable disposition, was very much injured, in attempting to. extricate himself. Being informed that the horse was very lame, I went to see him; and, upon exa- 
mination, found his near fore-leg punctired in the knee-joint, near the flexor tendon, and at ever motion of the joint, the sy novial fiuid pafsing through the orifice as if from a syringe. The horse was immediately properly secured, and I pafsed the probe into the joint, with an intention to examine if any extraneous substance remained in the wound, as I had reason to suspect it was caused from a splinter of wood, but could perceive nothing.

"THE orifice being large, I had small hopes of succefs, but resulved on trying what effeet the actual cautery would have, I got a piece of iron made into the form of a budding-iron, broad at the point, so as to completely cover the external opening, and blunt, that it might not penetrate too deep; which, being heated to a proper degree, I applied to the round, taking care not to injure the capsular ligament, and over it a large pledget of tow was properly secured; two quarts of blood were taken from him, and opening medicines administered. His diet was changed to warm mashes of bran, with a few oats, and a little good hay.

"I visITED him every day, and was grieved to find the joint become very much enlarged, and the eynovia continuing to pafs through the pledget of 
tow in large quantities, which I could only attri. bute to a diseased action of the glands.

"ON the fourth day, the horse being again pro. perly secured, I removed the drefsing, and found the orifice of the wound still open, but so small, as only to admit a probe. The motion of the joint keeping the wound open, by continually forcing the fluil through it, induced me, once more, to apply the cautery; which being done, the part was covered, as before, with a large pledget of tow. But being alarmed at the increasing inflammation, and enlargement of the joint, I thought it necefsary to apply a poultice on the fore part of the knee, so as not to cover the wound, for fear the eschar should slough away to soon. A little more blood was then taken from him, and some more opening medicines given.

"FInding the poultice prevented the inflammation from increasing, I continued it every day, but suffered the pledget of tow to remain on the wound about ten days, and kept the horse as much at rest as pofsible.

"ON removing the drefsing, I found the discharge completely stopped, and the wound filled up with healthy granulations. I then advised gुentle ex- 
Ercise, and a solution of coinmon alum in water, to wash the wound.

"THE horse, being still very lame, and the knee much enlarged, 1 ordered a strong blister of cantharides and lard to be applied round the knee, but not so as to cover the wound, with an intention, by the discharge it might produce, to relieve the part; and I found it had the desired effect. The horse was then sent to grafs, and in two months, contrary to every cxpectation, got perfectly well, and one joint was scarcely to be distinguished from the other."

\section{- Contused and tacerated Wounds}

APE seldom healed by the first intention, from the divided edges being unequal and ragged. The bleeding is seldom considerable; probably from the refsels being very much stretched before they were divided. The pain, swelling, and inflammation, are often very great.

THE first thing to be done is to remove any extraneous body that may be lodged in the wound; the parts are then to be brought as nearly into their natural situation as polsible. 
IF a part seens so much lacerated or contused, that it appears unlikely to admit of a sufficient circulation being carried through it, so as to preserve its living principle, it will then certainly be advisable to remove it. Neither suture nor plasters should be used, unlefs there seems very good reason to suppose that union by the first intention will take place. The inflammation brought on byt these wounds is very apt to terminate in mortification. We should, therefore, use every means in our power to keep it under, and encourage suppuration.

WHEN a muscle is rounded, it either generally soon heals by the first intention, or by suppuration and granulation; but wounds of tendons are much more troublesome, polsefsing very little vascularity, and therefore ircapable of suppuration. Spirits of turpentine, in cases of wounded tendons will be found the best application.

IT has been said, that a partial division of a nerve or tendon may be attended with very bad consequences; but these must arise merely from its being a punctured wound, in consequence of a tendon being wounded, a spasmodic contraction of the muscles may take place. Opium, in this case, 
may be applied to the wound, and given internally, joined with other antispasmodics.

\section{On Ulcers.}

BY an Ulcer is meant a solution of continuity, with lofs of substance, (not recently made,) dis-charging pus, or any foetid matter. They may arise from external injury, or from some local or general affection of the systern.

WE shall, in this place, only notice those ulcers which secrete vitiated pus; the callous and sinuous Ulcer.

THE cause of ulcers becoming vitiated, is in general owing to an indolent action of the parts, or from great irritation. The matter discharged - is thin, and of a greenish colour : this is what is called Ichor. When there are red globules mixed with it, and it is very fortid, it is called Sanies. When it is more risid, and the discharge is of a purplish colour, resembling coffee grounds, and fretid, it is termed Sordes. The ulcers discharging this matter are of a dusky red colour, and are attended with more pain and irritation, and tie grianulations appear pale and unhealthy. When the wlcer discharges vitiated pus, the ed gुes thickened 
and ragged, rising above the level of the skin, it called the callous Ulcer:

Emolient applications to these ulcers will, in general, affect a cure, except when they have been of long standing: it will then be necefsary to use stimulants or caustic; such as spirits of turpentire, nitrous acid, lunar saustic, boiling oil of turpentine, or the actual cautery.

Ir sometimes happers that the granulations; (commonly called proud flesh) when ulcers are healing, are too luxuriant, shooting out abore the level of the skin. In this case, we must have recourse to escharotics; such as mercury precipitate, or solutions of blue or white vitriol, verdigris; burnt alum, caustic in its solid form, or difsolved in water. After they are removed, dry tow, or tow spread with common turpentine, are the best applications.

THE sinuous ulcer is where there are sercral channels communicating with the ulcer, and discharging the matter secreted into it, and the matter from the ulcer pafsing into them, and kecping them distended, so that they cannot, unite. These are generally caused from the matter of the ulcer 
not having a free discharge, or by the improper application of bandages.

For the cure of these ulcers, it has been recommended to use injections; but they are often found to produce too great irritation.

WHERE we find bandages uselefs, or impofsible to be applied, we must either use the seton, or lay them completely open; but when the seton can be drawn through the sinus, so as to give a depending orifice to the discharge, it is the best means of procuring an union of the sides.

\section{On Fistule.}

FISTULÆ most frequently occur to the horse on the extremity of the neck, commonly called pole evil, or on the withers; but may take place in any other part.

Fistule is in general produced by bruises, causing abscefs, and forming sinuses.

WHEN sinuses have been of long standing, the granulations, on the inside surface, are very apt to become unhealthy, and secrete a thinish discoloured fluid, between ichor and pus, the orifices being 
prevented from healing the edges, tuck in, and $a^{*}$ degree of callosity takes place. The orifice is, in general, very small, and gives us no idea of the extent of the sinus.

A FISTUze is, in fact, a continuation of a disease, the parts being unable to remove the cause which first produced it, or its effects. Fistula may arise in any other part of the body, from extraneous matter lodged in a part, and continually keeping up a degree of irritation. As for instance, an exfoliated bone, or a bullet, \&c.; or it may happen fiom a diseased state of the parts, which are deep seited, and are generally indolent, and slow in their union; as a diseased bone, tendon, ligament, \&c. or from the matter in an abscefs not meeting with a depending drain.

In the treatment of fistuli, we should always endearour to remove immediately the cause producing it, if it remain. A perfect exposure of the fistulous sinus, by incision, is then the next object, so as to allow a complete exit for the whole of the matter. We must next endearour to bring it to the stite of a simple ulcer, by pouring on the part oil of turpentine, or olive-oil, heated to such a clegree as to produce eschar; afterwards drefs with common turpentine spread on tow, and frequently. 
wash the wound with a strong solution of alum in water.

THE nitrous acid, or strong aquafortis, has been found very useful in fistulous ulcers; the parts being touched with a feather dipped in it occasionally, and the above-mentioned drefsing applied afterwards.

Of Hiemorrhage, or Bleeding in general.

BY Hæmorrhage is meant an effusion of blood from any of its containing vefsels, into internal parts of the body, where there is no outlet; or upon an external surface, rendered so by accident.

WE shall first consider those where external treatment may be applied. It may either be arterial or venous, or both. If it is from an artery, the blood is of a florid red colour; and if from a large trunk, it comes out in an interrupted stream, the bleeding from veins is of a darker colour, and comes out in an uninterrupted stream. The dark colour does not always prove it to be venous: for some times, though it will at first fiow from a vein of a dark colour, yet the subsequent blood shall be of a florid red, owing to its pafsing from an artery to a vein.

BLEEDINGS taking place from arteries, are more dangerous than those from reins; and particularly 
from arteries near the heart, and which lie deep. In a rein the circulation is slower; and as veins lie more superfichlly, bleeding is more easily stopped. Blceding may take place either from a total or partial division of the coats of an artery, or from a diseased alteration of their structure.

BLEEDING may terminate by aecidental, or by artificial means; or, if it is suffered to continue for a length of time, in death. When arteries are divided, if they are not large, bleeding soon ccases. This arises from the muscular fibres which enter their structure, contracting their diameters and lengths, so as to obliterate their cavities ; the contractile power of them being greater than the impetus of the blood.

In the division of the larger arteries, where the powers of the circulation, and the elasticity of the vefsels are greater than their powers of contraction, we must not trust to it alone. It may sometimes stop the bleeding for a little time, but we may expect a return of it.

Buoor may be stopped, from the accidental manner in which the velsels may be divided, as by vicilent laceration, and other causes. 
Ir is observible, that, by instinct, all animals nibble off the navel-string of their young. Sowgelders, in castrating, draw out the spermatic artery to a great length, and divide it witi a blunt knife; yet, in neither of these cases, do we see bleeding tike place. When nature is insufficient to stop bleeding, we must have recourse to artificial means, such as styptics, ligatures, \&r.

Styptics are said to act in three ways. One is by disposing the vefsels to contract; the second, by disposing the blood to coagulate; and the third, by coagulating the refsels themseires. The first of this clafs is preferable, when we may depend upon its effects being permanent. Amongst these may be ranked the spirits of wine, oil of turpentine, the vitriolic and muriatic acids diluted, alum, balsam traumatic; oil of turpentine is, however, most preferable. Of the second chais we may mention the mid absorbent substances; as flour, lint, bole ammoniac, sponge; these, by absorbing the thinner parts of the blood, prove very useful. The third clafs are improperly called Styptics, as they destroy the refsels themselves, and produce eschar. Of this clafs are all cuustics, blue vitriol, boiling oil of turpentine, \&c. 
WHERE there is great difficulty in getting at a vefsel, we must apply the cautery, though much inconvenience may be produced by it; the impetus of the circulation frequently throwing off the eschar, and fresh bleeding ensuing. In using the cautery, we should be careful not to apply the iron too hot, as the eschar would almost immediately be thrown off, and the desired effect be frustrated.

THE treatment of hæmorrhages will depend on their causes. If styptic applications have been tried ineffectually to a large vefsel, we must use a ligature. In internal hæmorrhages, the oil of turpentine has been found very serviceable. It may be given from one to three ounces, in a solution of gum arabic, or mixed with gruel. Opium, in this case, is seldom found useful. If the knidneys are wounded, turpentine may be given often, and in small quantities.

THEse are the chicf ways of restraining bleed. ing: but we must recollect, that where bleeding takes place from a large artery, and we can take it up with a ligature, it ought always to be pre $_{\bar{Y}}$ ferred to styptic applications. 


\section{On Sprains.}

THESE next demand our consideration, as the horse, from the great exertion lie is frequently obliged to undergo, is very liable to receive injury in some of his joints.

IT is well known, that external force may be applied to a joint, so as greatly to strain and injure its ligaments, without absolute dislocation having taken place.

THIs, in general, is attended with extrarasation and swelling, the cellular membrane becoming distended, from an increased secretion of stroria, especially where the capsular ligament is loose; as in the joint of the hock or pastern. This is often succeeded by inflammation, and lofs of motion of the joint; at least there is considerable difficulty in performing it ; these parts, before nearly insensible, now becoming highly sensible and painful.

WHEN the sprain is recent, bandages impregnated with the following mixture, may efiect a cure:

Take sugar of lead, half an ounce; the best vinegar, one pint; rectified spirits of wine, four ounces: mix and shake then well together for use. 
But if, after using this mixture and bandages. six or eight days, no amendment is perceived, recourse may be to had the blister-ointment, which must be rubied well in all round the joint with the hand, and may be repeated, if necefsary, in eight or ten days; this seldom fails to effect a cure.

But if blistering the part fails, as is fometimes the case in violent strains, firing, in perpendicular lines, but so as not to penetrate through the skin, is our last resource.

THE following blister-ointment we have ever found the best: as it is easily made, and, if properly applied, has always the desired effect, and never destroys the roots of the hair.

Take cantharides in fine powder, one ounce; purified lard, if in summer, or the best olive oil, if in winter, four ounces: mix them well together for use.

THE above ointment may be made stronger or weaker, by adding or diminishing the cantharides.

SPRAins are likewise the cause of those diseases of joints called Bog Spavin, Thoroughpin, and Windgalls; which being principally 
enlargements of the bursæ mucosæ, and frequently communicating with the cavity of the joint, should never be laid open, although that operation is directed by almost every author who has wrote on farriery; as by that method very great inflammation, troublesome ulcers, and often incurable lameneis is the consequence. The same method as directed for the cure of strains, will be found the most beneficial in all these cases.

\section{On Bone Spazin, Splints, and Curbs.}

A Bone Spavin is a deposition of bony matter taking place on the inside of the hock-joint of all, but most frequently happening to young horses, causing lamenefs in a greater or lefser degree. The danger is in proportion to the quantity of bony substance thrown out, and to the nearnefs or distance it may be from the joint.

THE reason that young horses are more subject to this disease, appears to be principally owing to the bad method of shoeing made use of in most parts of England; for the common practice is to make the outside of the shoe much thicker than the inside; and, to complete the mischief, the outsıde heel is often turned up, which deprives the horse of a level and easy tread, and the 
joint not having attained its proper growth and firmnefs, is easily twisted or bent inward.

But we find that spavin sometimes takes place on the joints of horses that have never been shod; this is owing to the carelefsnefs of the owner, in permitting the horses to continue in the field a number of months, without paying any attention to their feet; which frequently growing irregular, deprives them of a level tread.

THE feet of young horses, when at grafs, should never remain unexamined above a month, or six weeks at most; and at that time all irregularities of growth should be removed. By this means the natural beauty of the foot will be preserved, spavins and splints prevented, and the horse early accustomed to the operations of the farrier.

THE consequences of the above causes are, that the head of the metatarsal or cannon bone becomes inflamed and enlarged: this proceeds from extrarasation taking place in the interstices of the bone, as is the case in soft parts. When the inflammation is suffered to go on, it generally communicates its disposition to the neighbouring soft parts, and by this means the periosteum, cellular-membrane, digaments, and muscles, are changed into 
and increase the size of the bone. This procefs is called the adhesive Osific Inflammation.

THrs adventitious bone is easily distinguished from the real bone by the roughnefs of its surface; and it often becomes a cause of anchylosis, or union of the joint. Whilst forming, it gives but very little pain, and seldom materially affects the constitution.

Spavin, splints, and curbs, may likewise proceed from violent blows on the part, causing inflammation.

WHEN any enlargement on the inside of the hock is perceived, it should be examined with the strictest attention; and if bony substance is perceived to be forming, medicines which powerfully promote absorption should be immediately applied; such as equal parts of cantharides and lard, with which the parts should be kept constantly moist, until the swelling is remored; but if the disease has remained a length of time, the following will pe found more beneficial :

Take sublimate mercury in very fine porrder, two drams; strong mercurial ointment, four ounces; let tnem be mixed weil together to make an ointment. 


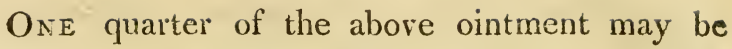
rubbed well upon the part with the hand, and repeated once a week; and, after a proper interval, the whole may be repeated, if necefsary. The body should be kept gently open, and one of the following mild diuretic balls, given every other day, for twelve or fourteen days; afterwards, one every six days.

\section{DIURETIC BALLS:}

Take yellow resin in powder, one pound and a half; common turpentine, one pound; Castile soap, twelve ounces: difsolve the resin and turpentine over a slow fire, then add the soap, first cutting it in small pieces; and after they are sufficiently incorporated, set them aside to cool, and form into balls.

THE common weight of these balls should be one ounce, the small balls about six drams, and the largest about an ounce and a half.

But if, after a sufficient trial, the above method should fail, fring, as recommended in the treatment of strains, must be advised, and the horse. sent to grạs. 


\section{Splints and Curbs.}

SPLNTS are depositions of bone found on the middle of the cannon or shank bone of the forelegs, but may likewise take place on the same part of the hind-legs.

CURBS are the same depositions taking place on the back part of the hock. The causes of these are the same as of bone spavin; and the treatment there directed, can only, in these cases, be of service; but when splints become very large, and cause great lamenefs, an expert operator may cut through the integuments, and remove them with a chifsel, taking care not to injure the suspensor ligament, or tendon.

\section{Recent Colds, or Cutarr.}

THERE is not any disease to which the horse is more liable than that which comes under the above denomination. This disease is principally owing to sudden changes of temperature; and experience shows, that a sudden change from cold to heat is more frequently the cause, than from heat to cold.

IT will ever be found, that when a horse has 
been exposed to a cold air all day, or pcrhaps for wreeks, and then removed to an hot stable, and fregiently covered with warm clotling, that the circulation will be increased to a great degree; whereby the glands of the nostrils become inflaned and obstructed, and only a thin humour, resembling water, is secreted, containing a quantity of neutral salts; which, as the parts are left undefended, act as a continual stimulus; causing great irritation.

In its incipient, or first stage, we observe that the nostrils look red and inflamed, and a thin humour is discharged. This is attended by a slight cough, and some degree of fever; the pulse is hard and frequent; a dulnefs of the eyes, sometimes with a defluxion of serum; a sorenefs of the throat; and food is often returned out of the mouth, owing to the irritation it causes.

As the disease and infammation increases, the horse becomes very dull, and a listlefsnefs to action takes place; the cough becomes more frequent; the glands under the jaw become intiamed and enlarged, and the fever increases, attended with. costivenefs. If the cough is violent, and long continued, it often lays the foundation of broken wind. 
THE first indication of the cure of catarrh, is to lower the circulation, by taking away two quarts of blood, and afterwards let a moderate warm mash of bran, with a few oats, be put into a nosebag, and secured upon the horse's head, so as to let the warm steam continually pafs up his nostrils. This method of using the mash is evidently the best: for the warm steam lubricates the mucous membranes, sheatlis and preserves them from the acrimony of the humours, and ultimately restores them to their proper action; by removing their tension.

THE intestines should be kept open by gentle alterative medicines; such as the following:

Take Barbadoes aloes, one ounce and a half; ginger in powder, half an ounce; soft soap sufficient to form the whole of a proper consistency: divide into four balls.

ONE of the above balls may be given every morning, until gentle purging takes place, and may be repeated occasionally.

If the irritation and cough continues to increase, after a due attention to the above directions, which is not often the case, it will be necessary to repeat the bleeding; and if the glands 
under the jaws become enlarged, the blister ointment may be applied, or a linseed poultice. If suppuration takes place, they may be opened with the lancet.

THe clothing should be moderately warm, and the patient should have frequent gentle exercise.

THE diet should be warm mashes of bran, with a few oats; or warm water-gruel, and a little good hay:

But we frequently find when horses have often been affected with cold, that there will continue to be a discharge from the nostrils, of a thick yellow or whitish matter, resembling pus, attended with frequent coughing, which often continues a long time; and, if not renoved, is productive of very disagreeable consequences; by causing diseases which are incurable.

For the removal of this discharge and cough, a continuation of the following medicine will be found very efficacious :

Take crude antimony in very fine powder, one pound; grains of paradise, two ounces; nitre, half a pound: mix them well together. 
THE above medicine may either be made into balls, with mucilage of gum arabic, or honey ; or may be given in powder, mixed with their food. The dose is half an ounce, morning and evening.

\section{On Fever.}

FEVER is a general inflammation of the system, frequently terminating in suppuration, or gangrene of some of the internal viscera, and death.

FEver may proceed from various causes; such as a sudden change of temperature from heat to cold, causing spasm of the external vefsels, whereby the perspirable matter becoming obstructed, is thrown back upon the circulation.

Or it may tale place from the horse having been heated by violent exercise, and immediately permitted to drink a large quantity of cold water, causing general spasm.

Ir may likewise take place from violent pain in any part of the body : for instance, spasm of the intestines, external or internal wounds, \&c.; but this is only symptomatic.

THE particular symptoms attending fever, from 
the two first causes, are a starting: of the coat or hair; an increased action of the heart and arteries; great restlefsuels and inquietude; great heat and thirst, attended by sweating, which is succeeded by universal coldnefs; the tongue white and dry, or clammy; lofs of appetite, \&ic.

As the fever increases, the pulse becomes strong, full, and quick; and sometimes intermitting, with a wildnefs of the eyes, difficulty of respiration, trembling; and, in its last stages, a copious discharge of tears from the eycs; the urine very high coloured, an exceeding quick ind obstructed pulse, stupor, death. .

ThE progrefs of fever is much more quick in the horse than in the human subject, frerguently destroying the patient in two or three days.

WHEN fever takes place from the above-mentioned causes, viz. sudden change of temperature from heat to cold, or the indiscreet use of cold water, our first care must be to lower the circulation, by taking from the patient two or three quarts of blood, and by administering such medicines as have a tendency to remove spasm, and promote perspiration, without increasing the cir- 
culation. For which purpose, the following prescription will be found excellent:

Take camphor, six drams ; nitre, and cream of tartar, of exch two ounces : powder and mix them well together, and add honey sufficient to make the whole of a proper consistency, and divide into four balls.

ONE of these balls may be given every six or eight hours; his clothing should be warm; and his diet warm mashes of bran; his drink should be warm water, with a little swcet bran or oatmeal sprinkled on its surface, or warm water-gruel.

IIIs body should be kept open, by the following clyster :

Take Barbadoes aloes in fine powder, half an ounce: difsolve it in two quarts of strong linseed tea.

LET this clyster, a little warm, be thrown up the rectum, by a bladder and pipe, erery five or six hours.

If the irritation and fever continue to increase after the above treatment, (which is not often the case) a lit le more blood may be taken away, and 
the camphor ball may be repeated, with the addition of ten grains of opium to each ball; or the following may be given with advantage:

Take purified opium, one dram; antimonial powder, two drams; nitre, and cream of tartar, of each one ounce and a half; honey sufficient to form the mafs, and divide into four balls:

ONE of these balls may be given every six hours, and repeated, if found necefsary.

If the fever is attended with costiveners, twenty grains of calomel may be added to each ball, and the clyster continued. By these means the fever will be removed, and the vefsels recover their proper action.

But as fever generally leaves the patient in a state of great debility, it will be necefsary, in a few days after it is removed, to adopt a more strengthening diet; such as a mixture of bran, oats, anct malt, sprinkled with warm water. And one of the following aromatic stumachic balls may be given every other day, which will complete the cure, and render the horse fit for duty :

Take grains of paradise, in fine powder, one ounce; ginger in powder, six drams; li- 
quorice, anise-seeds, caraway-seeds, in fine powder, of each two ounces; honey sufficient to form the whole of a proper consistency, and divide into eight balls.

\section{Inflammation of the Lungs.}

THE lungs are subject to inflammation, whicl is principally caused by sudden change of temperature from cold to heat, increasing the circulation to such a degree, so as to cause obstruction in their smaller refsels; which, if not timely remored, frequently cause, or lay the foundation of broken wind, or terminate in suppuration or gangrene.

Ir may likewise proceed from extraneous matter pafsing down the trachea, or windpipe, producing violent irritation.

But it most frequently is caused, in young horses, by violent exercise, and high feeding.

THE principal symptoms arising from the abore causes are, difficulty of breathing, with quick heaving of the belly, sometimes attended with a cough, the tongue hot and dry, the pulse full and quick, the fore-legs extended wide, the head 
langing down, and sometimes a discharge of matter from the nostrils, which frequently becomes yellow, a rumbling of the bowels, with costivenefs; the extremities cold: and it is a characteristic symptom of this disease, that, during its continuance, the horse seldom or never lies down.

As infammation of the lungs is quick in its progrels, too much care and attention cannot be observed in alleviating and putting a stop to its bad effects.

If the action of the heart and arteries is very great, there may be danger of suppuration or gangrene. In this case, bleeding from the vein on each side of the neck, at the same time, and from large orifrces, should immediately take place. Three or four quarts taken away in this, manner, will be found more beneficial than six or eight quarts taken only from one rein. If the pulse rise after this bleeding, which is often the case, we may renture to repeat it in sixteen or twenty hours afte:, or according as the symptoms may direct, and let the following medicines be given :

Take antimonial powder, one dram and a half; nitre and crean of tartar, of cach ong ounce and a half; mix them well together, and divide into four parts. 
ONE of these powders may be given in a quart of linseed decoction, and repeated every two lions.

THE body may be kept open with gentle stimulating warm clysters.

THE horse should be kept in a moderate degree of temperature, avoiding, as much as polsible, his being exposed to a current of air. His clothing should be rather warm, and he would be best in a place where he could have the liberty to walk.

His legs should be well rubbed half an hour, four or five times a day, with a cloth; and his diet should be warm mashes of bran, or warm wateryruel.

IF by this method of treatment the symptoms do not abate in two days, it will be necefsary to take away a little nore blood, and endeavour to prevert the formation of matter taking place in the lungs, by administering such medicines as powerfully determine the blood to the kidneys and intestines, and which also, by bringing on purging, opens the body, and finally removes the Gisease.

Take calomel, one scruple; antimonial powder, half a dram; cream of tartar and nitre, of 
each three drams: mix them well together, and difsolve them in a quart of linseed de: coction.

THIs mixture may be given every two hours, until purging takes place; and its action may be promoted by the following clyster :

Take linseed, three ounces, boil it in four quarts of water half an hour; pafs the decoction through a coarse cloth, and difsolve in it half an ounce of aloes in fine powder.

LET this clyster, a little warm, be thrown up the rectum two or three times a day.

By this method of treatment, purging generally. takes place in twenty-four hours, and the disagreeable symptoms gradually subside.

A ROWEL on each side the chest, will likewise be found very useful in promoting resolution.

AFter the action of the physic is over, and until all the symptoms of the disease are completely removed, it will be necefsary to keep the body open; for which purpose, the abore-mentioned clyster may be used every other day, and the linseed decoction, with the nitre, cream of 
tartar, and a few grains of the antimonial powder, may be continued with adyantage.

WE are happy to say, that where the above method of practice has been adopted on the first appearance of inflammation of the lungs, it has always answered our highest expectation; and it has often been found to remove the disease in its more adranced stages.

\section{Broken Wind.}

IT frequently happens, that when the acion of the blood-vefsels of the lungs have been increased to a great degree, and the inflammation produced, terminates without suppuration or gangrene, that the coagulable lymph is extravasated, or thrown into, and plugs up a part of the air-cells, which prevents them from performing their proper functions, and the animal not being able to take in a proper quantity of air, is obliged to inspire, twice in the time which before only took up one inspiration, and thus causes a double heaving of the flank or belly.

The other cause of broken wind is riolent coughing, or violent exercise, inmediately after the stomach has been distended with much food or 
water. This causes great opprefsion of the chest, and difficulty in breathing, and a rupture of the air-cells is the consequence. Thefe ruptured aircells form on the surface or edges of the lungs, and are never completely emptied in expiration. When this is the case, the animal not being able to expel the air at one expiration, another immediately takes place, and is attended with a very high rising of the flank, which suddenly falls. This action goes on in regular succefsion.

IT is observable, that large quantities of wind is found in the intestines of broken winded horses, which may probably be owing to the great and long-continued action of the belly.

From a consideration of the causes of broken wind, it must evidently appear, that it is an incurable disease, and our intention must be to mitigate it as much as pofsible. This is best done, by giving the animal small quantities of the most nutritious food and water at a time, and often, in the the day; by these means preventing, as much as pofsible, prefsure on the chest, to which may be added occasional doses of gentle purging medicines to kecp the body open. 


\section{Diseases of the Liver.}

\section{Jaundice.}

The Jaundice, or Yellows, is a disease which seldom affects a horse; farriers often mistake some other morbid affection of the system for this disease.

In the human subject, it is principally caused by inspirated bile forming a concrete in the gallbladiler, and thereby obstructing the secreted bile; but the horse, having only a small tube which conreys the secreted bile into the intestines, is not so liable to obstruction from concretes.

Thovgr the bile is not so liable to be obsructed, yet it sometimes takes place, and is more frequently caused by inflammation of the liver, than concrete. When this happens, the secreted bile becomes obstructed, and is forced into the hepatic veins, or taken up by the lymphatics, and carried into the circulution. This is discorered by the cyes appearing of a dusky yellow colour; the mouth, lips, and saliva acquire a yellowish cast; the animal is dull and sluggrish, and refuseth his food; his urine is of a dark brownish colour, and when on the ground appears red; the animal 
is very costive, his excrements hard, and have the appearance of a yellowish or greenish clay; his pulse irregular with fever. 'The disease and fever increasing, end in delirium and death.

IT has been the general rule, when the patient was affected with the jaundice, to let blood; but bleeding, by producing great debility, and promoting absorption, must evidently have a tendency to increase the disease.

Brisk purges, joined with calomel, will be found of the greatest benefit in removing these obstruc. tions of the liver.

Take Barbadoes aloes in powder, five drams; calomel, one dram ; mucilage of gum-arabic fufficient to make the ball.

Let the above be given every other day.

WHEN the horse has taken this medicine three or four times, and his eyes and excrements begin ro change colour, leave off medicine, and give him nourishing food; such as ground oats and beans, or a quantity of bruised malt, on which warm water has been sprinkled; and, after a remifsion of five or six days, the following ball: 
Take Barbadoes aloes, three drams; calomel, half a dram; ginger in powder, one scruple; conserve, or honey, sufficient to make the ball.

Four of these balls may be made, and ore given every week, which will, in general, complete the cure.

WHAT we have advanced respecting inflanimation of the liver, is only to be understood as a partial or chronic inflammation. When it becomes acute, we can hold out very little prospect of relief; it frequently destroying the patient in fifteen or twenty hours, which does not allow of any effectual operation of medicine.

WE will however endeavour to point out the best method of prevention: This acute inflammation of the liver arises from hot stables, and where a large quantity of moist litter is suffered to remain under the horse ; it is more frequent in barracks, where a great number of horses are together, than in the stables of gentlemen, where it very rarely happens.

IT will be best prevented, by removing the causes above mentioned, and frequently giving the following gentle phyfic: 
Take Barbadoes aloes, one ounce and a half; ginger in powder, one ounce; soft soap, sufficient to form the mafs: divide into six balls.

ONE to be given every morning, until they gently purge.

THE smptoms of acute inflammation of the liver are, difficulty of breathing; the mucus of the mouth very foetid; swelling of the belly; costivenefs; violent pain; staggering, on being put in motion; and fometimes palsy of the under jaw ; convulsions; the eyes drawn into the head; ending in death.

EXPERIENCE has shown, that, in this case, bleeding is attended with evident bad effects, and that we can only rely on small dozes of calomel, about half a dram, with the same quantity of antimonial powder, and half an ounce of cream of tartar, frequently giren, until gentle purging takes place: and we can safely pronounce the case favourable, if the patient is not destroyed before these medicines begin to operate. 


\section{Diseases of the Kidneys.}

\section{Supprefsion of Urine.}

ThE diseases to which the kidneys of the horse are liable, may be divided into two; viz. a supprefsion, or a too copious discharge of urine: And, first, we shall consider supprefsion of urine.

THE horse is very liable to have his kidneys inflamed, from the great prefsure to which his loins are exposed. Concretes of calcareous matter are more liable to generate and remain in his kidneys and uriters, from their horizontal position: but the most frequent cause of the kidneys being inflamed, is from the indiscreet use of strong diuretics.

THE general symptoms observable in infiammation of the kidneys, are ; universal coldnefs; restlefsnefs; great sense of pain on prefsure being applied to his loins; his hind-legs extended wide; frequent, but fruitlefs attempts to stale; his urine, if any is voided, it is in small quantity, and red; and upon examining, by introducing the hand up his rectum, his bladder will be found empty : as the disease increases, it is attended with quicknefs of 
respiration; full and quick pulse; cold sweats; paralytic affection of the hind legs; frequently ending in death.

WHEN we find the patient attacked with this disase, our first care should be to lower the circulation, by" taking away two or three quarts of blood, according as the inflammation is more or lefs violent; and the following medicine may be griven to open the bowels:

Take Barbadoes aloes in powder, half an ounce; linseed meal, three drams; ginger in powder, one scruple; conserve suffcient to make the ball.

LARGE clysters of warm water should frequently be thrown up the rectum; and his loins should be fomented with double flannels, dipped in warm water. No diuretics or blisters should be used, as they would only tend to stimulate the kidneys, and increase the disease. Two ources of gum arabic powdered, and difsolved in two quaits of water, to which may be added half an ounce of tincture of opium, may be given three or four times a day. His clothing should be warm, and his diet warm mashes of bran: When he begins to make water fireely, a little nitre may be mixad with his drink, which will complete the cure. 
If the symptoms are not remored or abated in trienty-four hours, a little more blood may be taken away, and the above method continued.

\section{Diabetis.}

WE now come to consider the causes of Diabetis, or a too copious discharge of urine : the principal causes of which are, obstructed perspiration, causing a too ofreat determination of serum to the kidneys, or from too long a course of stimulating diuretics. These cause a relaxation and alteration of the tone of action in their vefsels : it may likewise arise from violent exertion.

THis disease will easily be distinguished from others of the kidneys, by attention to the following symptoms: The surface of the body cold; the coat rough; lofs of appetite; a constant thirst, the animal often craving for water; a frequent and copious discharge from the bladder, which is not truly urinous, but of a pale colour, and an insipid or sweetish taste; his pulse is weak and quick, attended with a gradual wasting of his flesh. If the disease be of long standing, it is very cliffcult of cure. Warm mashes and clothing will be found of great service; to which may be joined the following course of medicines: 
Take Peruvian bark in fine powder, twelve ounces; grains of paradise, two ounces; gentiar in powder, three ounces; honey sufficient to form sixteen balls.

ONE of these balls may be given every morning; and, if required, the whole may be repeated. The horse should be gently exercised every daý.

\section{Diseases of the Bladder.}

THE Bladder of the horfe is subject to spasm on its neck, and inflammation, producing different diseases. We shall first consider the latter.

INFAMMATION of the bladder may arise from a diseased action of the mucilaginous glands which are between its coats, so as to prevent the mucus from being secreted in sufficient quantity, to afford protection against the irritation of the secreted urine. Or it may arise from calcareous concretes pafsing from the kidneys, by the ureters, into the bladder, causing violent irritation.

THE symptoms of inflammation from these two causes are much the fame, viz. universal coldnefs of the extremities, frequently attended with cold sweats; pulse quick; his hind legs are extended 
wide; with a constant attempt to stale, and the urine continually dischargéd, but in small quantities. This is owing to the kidney's continuing to secrete the urine; and the smallest quantity, acting as extraneous matter, excites the bladder to contract and an endeavour to expel its contents. When this is the case, our intention of cure must be directed to the removing of the inflammation; and giving such medicines as may bring the vefsels to their proper action.

The inflammation may be removed by frequent bleeding in small quantities, according to the strength of the parient. His drink should be mucilaginous fluids; such as the following :

Take linseed bruised, half a pound; pour upon it two gallons of boiling water; let it stand until nearly cold, and strain it through a coarse cloth; then add four ounses of gum arabic in powder, difsolved in one quart of boiling water, to the above, and stir them well together for use.

ONE quart of this mixture may be given every four hours, or may be used as his common drink. Large clysters of warm water may be thrown up his rectum with great advantage. 
OPIUM has occasionally been found serviceable: in this disease ; and, when deemed necefsary, may be used in the following manner:

Take of the best opium in powder, one dram ; linseed in powder, half an ounce; mucilage of gum arabic fufficient to form the ball.

THE above ball may be given every other day; but if the disase proceeds from calculi, we have but small hopes of effecting a cure. We can only mitigate the symptoms, by a frequent use of the medicines before advised.

After the symptoms are removed, a courfe of the balls, as recommended in page 82 , may be given with advantage.

IN spasm of the neck of the bladder, the symptoms are similar to those of inflammation of the kidneys; supprefsion of urine being the consequence*. This disease is easily distinguished from those of the kidneys; by the hand being intro-

* This disease most frequently proceeds from a too long. retention of urine on a long journey, or too long continued exercise; the horse not being permitted to stale, his bladder becomes so much distended by the accumulating urine, as to lose its contractile powers. 
aced up the patient's rectum, the bladder will be found much distended, which is continually increasing; and, if not speedily relieved, becomes paralytic, and is rendered incapable of its usual powers.

IN this disease we must abstain from the use of diuretics, and all fluids, as much as pofsible. Bleeding may be used frequently: large and often repeated clysters of warm water will be found very useful : opium, to the amount of two drams, may be given with advantage. But if the above methods fail, and the disease continues to increase, our last recourse must be to puncture the bladder, by the rectum, with a small lancet, which will give immediate relief. 


\section{Diseases of the Intestines.}

DISEASES of the INTESTINES may be divided into two kinds, viz. 1st, Cholic or Gripes; 2d, Dicirroea or Loosenefs; and may proceed from different causes.

\section{1st, Of the Cholic or Gripes.}

THE cholic, or spasm of the intestines, may arise from violent exercise, or from the horse being permitted to eat too much green herbage, or from bad hay, new oats, \&c.; or it may proceed from strong purgatives administered when the boweis are over-loaded with crude vegetable food. This kind of cholic is most dangerous, as it frequently, by causing violent intiammation, terminates in gangrene: it may likewise proceed from costivenefs.

But from whatever cause it arises, it is attended with the following symptoms; viz. violent pain, and great restlefsnefs; his extremities cold; the pulse rather guick, and respiration increased: he fiequently attempts to lie down, but rises up immediately; his hind extremities are drawn under fim; he frequently strikes his belly with his hind 
legs, and always attempts to lie on his back and roll.

If inflammation takes place, his pulse becomes more hard and frequent, attended with a clammy drynels of the mouth and tongue; partial sweats take place; he continues to strike his belly with his hind legs, and to lie down, but never attempts to roll.

IN all cašes of gripes, it will be necefsary to take from the patient two or three quarts of blood im. mediately, which may be repeated, if required; and if not attended with inflammation, the following ball may be given :

Take Barbadoes aloes in porder, three drams; Venice turpentine, two drams: $\operatorname{mix}$ and. form the ball.

THE above ball may be repeated every twelve hours, if the symptoms do not subside, or until it purges; and large clysters of linseed decoction may be thrown up the rectum with great advantage.

From two to four ounces of common spirits of turpentine, in two quarts of gruel, given after 
previous bleeding, has frequently been attended with succefs.

If the infammation is great, so as to endange? the life of the patient, we must bleed very freely and frequently; large clysters of linseed decoction should be often repeated, and the belly often fomented with flannels dipped in water, as hot as the patient can bear, without injury; and one pint of cold drawn linseed oil may be given every six bours. But no purgatives, or other -medicires that have a tendency to stimulate, or cause irritation, should be given, as they would only be a means of increasing the disease.

His diet may be warm mashes; his clothing. should be moderately warm; and, when unattended with inflammation, gentle exercise will be found very beneficial. But in inflammation of the bowels, exercise would prove injurious.

\section{2d, Diarrhea or Loosenefs.}

IS a complaint in which the intestines are solicited to a too frequent discharge of their contents.

THE principal canses of diarhoea are, previous costivenefs; indigestion, which is known by bits 
of hay, and slimy matter, or mucus, being mixed with the fœeces; from violent purgatives ; and from a too great secretion of bile.

The symptoms are pain, flatulency, distention, and irritation of the intestines, accompanied with frequent purging; frequent and small pulse-heat, and thirst; sometimes cold sweats, attended with spasm of the bowels, and other parts of the body.

THE causes of diarrhœa being known, will point out to the practitioner the best method of cure. If it arises from previous costivenefs, it may be only an effort of nature to ease the burdened intestines of the obstructing matter, and seldom proceeds to that degree so as to become dangerous: and the medicines in this case, (if any is required,) should be of the mucilaginous kind.

Take gum arabic, four ounces; difsolve it in four quarts of water; to this may be added a few handfuls of oatmeal: this may be his ordinary drink. His food should be equal parts of ground malt and oats, sprinkled with warm water.

AND the following mild purgative may be given: 
Barbadoes aloes, three drams; cream of tar tar, three drams; ginger, one scruple: soap sufficient to make the ball.

Ir the disease proceed from indigestion, we must endeavour to restore the stomach to its proper tone of action; for which purpose, let him take the following medicine:

Take grains of paradise in powder, two drams; powder of gentian and powder of Columba, of each three drams; powder of ginger, one dram: honey, sufficient to form the ball.

THE above ball may be given every morning and evening, for six or eight days, or longer, if required.

IF it proceeds from violent purgatives, we must use such medicines as have a tendency to allay pain, and are at the same time astringent and mucilaginous, so as to sheath the intestines from the irritating matter; for which the following is excellent :

Take gum arabic in powder, one ounce, dissolve it in two quarts of boiling water; and, when cold, add half an ounce of tincture of opium. 
THE mixture may be given every six or eight hours : or it may be given in the form of a ball.

Take gum arubic in fine powder, six drams; pure opium, one dram; mucilage fufficient to form the ball.

ONE of these may be given every day, until the loofenefs is stopped. Let the patient's drink be warm gruel, which may be given immediately after the ball.

BuT if it proceed from a too great fecretion of bile, which may be known by the bile appearing in, and tinging the excrements of a dirty brown or reddish colour, we must, in this case, endeavour to correct the liver, and at the same time to put a stop to the irritation; for which the following prescription will be found very useful:

Take calomel, the best opium, of each half a dram; linseed meal, half an ounce; conserve sufficient to form the ball.

ONE of the above balls may be given every morning and evening until the disease is remored.

IN all the above cases, gentle exercise, with warm clothing, will be found advantageous. 


\section{Sleepy and Mad Siaggers}

ARE the same disease, only differing in degree, caused by prefsure on the brain.

PRESSURE on the brain may happen from a too sudden change of temperature, increasing the action of the heart and arteries to a great degree, whereby the refsels of the brain become distended; or fiom extravafated fluid, from a rupture of some of its vefsels, which may proceed from sudden violent exercise; or it may take place from a fracture of the skull by violent blows, \&c. or from a diseased action of some of its lymphatics, causing hydrocephalus, or dropsy of the brain.

STAGGERS is sometimes caused in a milder degree by other diseases; such as jaundice, fever, indigestion, and sometimes from the stomach and intestines being much irritated by bots, worms, \&c.

$\mathrm{ON}_{\mathrm{N}}$ the first appearance of this disease, the animal becomes comatose or sleepy; and while standing, his head is continually hanging down; great listlefsnefs to motion; dulnefs of the eyes; obstinate costivenefs; and lofs of irritability in a very great degree. This stage is what may be termed Slecpy Staggers. 
BuT if this complaint is not soon removed, it becomes more violent, and generally terminates in what is called the Mad Staggers.

THIs stage of the disease is attended by a wild staring of the eyes; and when the animal attempts to move, he staggers, runs round, and falls down, as if drunk; delirium then takes place, attended with convulsions, and sometimes locked. jaw ; most frequently ending in death.

BEFORE we attempt the cure of the staggers, we must, by a strict and minute examination, endeavour to find out the cause. For if it proceeds from an increased action of the blood-vefsels; from. change of temperature; bleeding from a large orifice, or, what is better, from both veins of the neck at the same time, to the amount of four or five quarts, will be attended with the greatest advantage; and one of the following balls may be given immediately :

Take Barbadoes aloes in powder, ten drams; calomel, one dram; ginger in powder, half a dram; honey sufficient to make the ball.

THE action of the above ball will be much accelerated by warm clysters, composed of half an ounce of powdered aloes, to four quarts of water. 
If staggers arise from extravasated fluids prefsing on the brain, the horse will, on attempting to turn or move his head, become delirious, stagger, turn round, and fall down. Extravasated fluids, or lymph prefsing on the brain, is not easily discovered; though, upon the above symptoms taking place, we may, with reason, suspect this to have been the case. Our best methods of practice, in addition to the medicines; \&c. above recommended, will be to cut the hair close on the top of the neck and head, and apply a strong blister, composed of equal parts of cantharides and purified hog's lard, which may be repeated.

IF the disease is caused by a fracture of the skull, removing the fractured part or parts with bleeding, and low diet, may effect a cure.

If it arises from other diseases, such as jaundice, it is then only an effect. In these cases, we must use such medicines as are directed for removing jaundice.

\section{Farcy}

IS a disease of the lympatic system. Diseases of the lympatics seem at present to be very little understood, as well as the methods of cure; but that 
they are subject to the same diseases as other vefsels, viz: inflammation and suppuration, we think is evident.

IN the horse, a diseased action of these vefsels constitute what is commonly called Farcy, which has been generally understood to be a disease of the veins, produced by sizy blood; farriers having been led into this errer, by observing it to proceed in the track of the external blood-vefsels, and from being unacquainted with the course of the lymphatics, which always accompany the veins. -

WHEN these vefsels become diseased, they form corded tumours, which are called Buds*. These buds are principally, in the incipient stage, of the farcy, on the inside of the thigh, fore-arm, and on the neck and shoulders, beginning at the extremities, and gradually proceeding nearer to the source of circulation; their obstruction causing odematose sweling of the legs; and, as it increases, the whole system puts on the same appearance.

These buds at first, when only in a state of inflammation, are very painful, but nearly insensible,

* These buds putting on a corded appearance, is owing to the great number of valves found in these vefsels. 
after suppuration has taken place; and; on open ing them, matter resembling pus sometimes, mixed with blood, is discharged, and the opening forms an ulcer, which is difficult to heal.

WHEN, in its later stages, the horse loses his appetite, and becomes very much debilitated, the tumours break through the skin, and discharge a fotid sanies, and the nostrils become affected, which frequently terminates in glanders and death.

BEFORE we endeavour to point out the cause of farcy, an attempt to investigate the use of the lympatics, which form a principal part of the absorbent system, may tend to throw some light on the subject. For as nature has formed vefsels on the surface, and in the cavities of the animal body, for the purpose of secretion; so it has been equally provident in furnishing a number of vefsels which perform the office of absorption, and which counteract any error of secretion.

Thus when fluids, or any other matter which may injure the animal œconomy, become extravasated, or thrown out in any of the internal cavities, or into the cellular membrane, it is frequently taken up by the lymphatics, and carried. into the circulation to be thrown out by stool, urine, or perspiration. 
That these vefsels equally extend to the surface, is evident; for if turpentine be applied to the skin, it very soon pafses to the kidneys, and is discovered in the urine by its smell; and a blister of cantharides has frequently been known to affect the urinary pafsages:

WHEN these veisels are gently stimulated, they will remove cartilage, bone, \&c. as in spavin and splints; and obstinate diseases of the eyes ofter owe their cure to the action of these vefsels alone.

From what has been said; we may conclude, that the causes of farcy are, principally, putrid matter coming in contact with the skin, altering. the action of these refsels, and causing inflammation, \&c. Change of temperature, by producing: great debility; may, be another cause. Want of exercise and cleanlinefs may have a tendency to produce farcy. It has been known to take place after the cure of obstinate grease*, and always from the absorption of the matter of glanders. In short, any cause producing long-continued debility, may produce farcy.

* Or by absorption of matter from old ulcers on the fetlock joints. 
WE shall now endeavour to point out such a method of practice as we have found most beneficial in the cure of farcy.

As farcy generally takes its first rise in the extremities, and proceeds gradually until the whole system becomes affected, it will be the most advantageous method of practice, to endeavour to stop the progrefs of the disease on its first appearance; for without we are able to effect this, little hope remains of the patient's recovery. For this purpose, we should draw a line the whole length of the diseased lymphatic on each side, with the common firing iron, heated to a proper degree, and then to open the tumours with the lancet; or, which is better, the hot budding iron, and to penetrate deep, so as to divide completely the diseased lymphatic, and prevent any future communication; and let the whole of the matter be prefsed out of the orifice by the fingers.

THE ulcers which are formed by these means, may be washed clean with warm water four or five times a day, and after drefsed with oil of turpentine, and the following course of medicine may be adopted :

Take common antimony in fine powder, one pound and a half; nitre in powder, one 
pound; grains of paradise in fine powder, half a pound; honey sufficient to form the mafs of a proper consistency : and diride into forty-eight balls.

ONE of the above balls may be given to the horse every morning and evening; his clothing should be moderately warm; and he should have a brisk gallop, to promote perspiration two or three times a day. His dict should be of the most nourishing kind; such as bruised or ground malt, mixed with ground oats and beans, and good old sweet hay.

If tumours or buds arise in any other part of the body, the above treatment may be used; and, if found necefsary, the balls may be repeated. It will be necefsary to keep the horse separate during the cure, as the matter of farcy is considered as infectious.

\section{Grease.}

THE Grease is a disease which more frequently attacks the hind legs of horses than the fore 'egs, but sometimes affecting both, causing inflammation, swelling, and ulcers. 
The causes which produce the grease are, principally, sudden change of temperature, hot stables, too high or low feeding, joined to want of proper exercise and cleanlinefs; or it may proceed from: some other disease in the constitution, or from a termination of inflammation, whereby the thinner parts of the blood may be thrown into the cellular membrane, and not being absorbed, falls down to the extremities.

ON the first attack of this disease, the hind legs: appear œdematous, particularly about the pastern joints, and the cellular membrane is filled with a fluid; where, if from want of proper care, exercise, \&c. it is suffered to remain, it becomes acrid, and causes inflammation, swelling, and tension. As the disease increases, the inflammation becomes more violent, the heels crack, and discharge very offensive matter, and the vefsels take on the same action as those of the feet, and horny substances are formed on the fetlock joint; the edges of the cracked skin becomes callous, refufe to unite, and obstruct the growth of new flesh; and sometimes the inflammation runs so high as to affect the capsular ligament of the joint and the bones, frequently causing a stiff joint.

If this disease is in its incipient stage, the horse 
seldom loses his appetite; but, if in its more advanced stage, he becomes very thin, loses his appetite and rest; being prevented by pain from lying down.

THE grease, in its first stage, is very casy; but if permitted to remain long, will be found very difficult to cure.

OUR first care should be to remove the inflammation and tension, and by that means restore the vefsels to their natural proper tone : for which intention, let a large poultice, composed of equal parts of bran and linseed meal, very warm, be applied all round the leg, and when cold repeated; and on changing them, let the patient be gently exercised for half an hour ; if the skin is cracked, let any dirt which may be contracted by exercise, be washed away with warm water, and the ulcer be sprinkled with a little powdered alum, and then the poultice may be applied. This treatment may be continued ten or twelve days, or longer if found necefsury; at the same time let the horse take the following medicine :

Take Barbadoes aloes in powder, one ounce and a half; calomel, one dram; ginger in powder, two scruples; honey sufficient to form two balls. 
ONE of these may be given immediately, and the other after an interval of thirty hours. His diet, whilst taking the above-mentioned balls, may be warm mashes of bran.

These balls will gently purge and cleanse the intestines. It will be necefsary, after the purging is over, to adopt a course of diuretics: six drams, or one ounce of the diuretic balls, page 60, may be given every other day, for a month, or until the cure is completed.

WHEN the inflammation is removed, the ulcers may be washed with the following mixture:

Take alum in powder, one ounce; Roman. vitriol, one dram; water, one pint.

This mixture may be used three or four times a day.

IT sometimes happens, when the grease is become very inveterate, and a great quantity of horny matter is thrown out, that the above method fiils of having the desired effect : in this case, the horn must be removed by the knife, or actual cautery, and the hair must be cut very close; and, after applying a poultice a few days, a blister, of equal parts of purified hog's lard, and finely- 
powdered cantharides must be rubbed well over the parts, and the horse turned to grafs. The blister may be repeated every fortuight, until the cure is completed.

\section{Hange.}

THE Mange is a cutaneous disease, attended with eruption, and lofs of hair.

THE causes of mange are sudden changes of temperature, hot stables, bad diet, joined to want of cleanlinefs, the perspirable matter being never properly removed, and frequently mixed with dust, \&c. completely plugs up the external vefsels, whereby they become obstructed, and a diseased action takes place. It may also be caused by infectious matter coming in contact with the skin.

THE principal symptoms of mange are, the horse growing very thin, without any apparent cause, attended with a starting of his coat; this is soon followed by eruptions, which discharge a thick yellowish matter, forming a kind of scurf, which peels off, and is succeeded by fresh eruptions, and the hair falls off. This, though partial at first, soon spreads all over the body, and is at- 
tended with an itching, causing the horse to rub against every thing he comes nigh.

WiтH duc attention to cleanlinefs, the following medicines will very soon remove this disease:

Take prepared hog's lard, one pound; sulphur yivum, half a pound; fine powder of white hellebore, three ounces; mix and add olive oil sufficient to make a soft ointment.

A NECESSARY portion of this ointment should be rubbed well with the hand all over the affected parts, or where there is the least appearance of any eruption, and repeated after an interval of three days. Two or three applications of this ointment are, in general, suficient to complete the cure.

'THE following medicine may be given with advantage in this disease; it will be found excellent for removing cutaneous obstructions, improring the appetite, and promoting condition.

Take antimony in fire powder, eight ounces; grains of paradise in fine powder, three ounces; mix and add Venice turpentine sufficient to form the mafs of a proper consistency, and divide into twelve balls: one of which may be given every other day. 
As this disease is considered as being infectious, it will be necefsary to keep the horse in a separate stable until the cure is completed.

\section{Strangles.}

THE Strangles is an inflammation and enlargement of the thyroide and maxillary glands, commonly attacking horses when they are from three to five years old, seldom later. It is supposed to be infectious; but this supposition is, in all probability, owing to the number of young horses affected at nearly the same time.

THE causes which have a tendency to produce inflammation of these glands are, any sudden change of temperature, high feeding, and violent exercise. These soon produce an increased action of the heart and arteries, particularly in young horses: by this means, the glands are stimulated, and their action increased to such a degree as to produce obstruction, inflammation, \&c. : in this disease we always find the mucous membranes affected.

THE common symptoms attending strangles are, an enlargement of the glands under the jaw, and sometimes it extends to the glands of the neck; it then becomes more dangerous. These cause a 
difficulty in breathing, and in degultition or swal. lorving; and his food is returned out of his mouth, owing to the irritation it causes on the larynx and plarynx, or top of the throat.

THFRE is sometimes a rattling in the throat, sulnels of the eyes, hard and quick pulse, with fever; the patient is in general costive, and a discharge takes place from his nostrils, attended with 2. slight cough.

ON our first perceiving an enlargement of the glands on the neck, or under the jaw, it will be necefsary to determine whether we should attempt the cure by resolution or suppuration: If the glands are but slightly inflamed, it may be best to attempt resolution. For which purpose, let two or three quarts of blood be taken away immediately, and the following gentle purge be given :

Take Barbadoes aloes in powder, four drams; calomel, one dram; ginger in powder, one scruple: mix, and add mucilage of gum arabic sufficient to form the ball.

LET also the following blister ointment be applied. fo the parts: 
Take hog's lard purified, three ounces ; ointment of yellow resin, one ounce: nix well together, and add cantharides in fine powder, one ounce $*$

But if the gland's are found to be much enlarged, it may perhaps be better to promote suppuration, by applying a large poultice, composed of equal parts of bran and linseed meal, made of a proper heat with hot water; which may be known by a person being able to bear his hand in it without pain. This poultice may be changed as often as it becomes cold; and when the tumour feels soft, and matter is formed, it may be opened with the knife or lancet in the mopt depending part, and its contents prefsed out with the fingers; the parts may be washed three or four times a day with warm water, and left to heal of themselves, which is accomplished often in a few days.

In both these cases, the diet should be warm mashes of bran, gruel, \&c. Warm cloathing, with gentle exercise, wili afsist much in promoting the cure.

* A part of this ointment may be rubbed well on the part with the hand, and may be repeated every three days, as long as found necefsary. 


\section{Hide-bound, Bots, and Worms.}

WHAT is understood by Hide-bound, may be said to be an effect rather than a disease; for its priucipal causes appear to be bots in the stomach, or worms in the intestines. These, if in sreat quantities, as is often the case, deprive the animal of his proper portion of nutriment, and Teep the stomach in a constant state of irritation. Bad ciet, inattention, and want of cleanlinefs, may inkewise produce this disease.

IN this disease, the horse is observed gradually to put on the appearance of extreme poverty, without any apparent cause; he becomes dull and languid; he appears in a state of great debility, and sweats much, on being moderately exercised; lis excrements become black and offensive; his coat starts, and his skin, by its complete adhesion, seems as if it were glued to his ribs*. It may be observed, that the appetite is seldom materially injured, except in the more advanced stages of this disease.

* One certain sign of the existence of bots and worms, is a yellowish powder appearing on the anus. 
THE first intention of cure is, if pofsible, to find out the cause; for if it only arises from bad food, or want of cleanlinefs, a more generous diet, with a few gentle purges, to which may be added walking exercise, and proper attention to cleanline $\mathrm{s}_{\mathrm{s}}$, will, in a little time, effectually remore every appearance of this complaint.

But if it proceeds from bots or worms, which is most frequently the case, other means must be used; the most effectual of which we shall endeavour to point out.

As the bots are, when in large quantities, very destructive to horses, by depriving them of nutriment, preventing digestion, and injuring the stomach, in which they are generally found; and as little has been offered to the public respecting their origin, and the means by which they are conveyed into the stomach, we shall first endeavour to point out the information which recent observation has furnished respecting them.

THE bots are a species of fly-worm, produced from the eggs of the hæmorrhoidalis, a two-winged fly, of the genus œstrus, and nearly of the size of the humble bee, which deposits its eggs in the rectum of horses, and occasions great torment to them. 
THE worms of the human subject have not been longer known to the world than those of the horse; and the farriers, in all ages, who have undertaken the care of these raluable animals, have had their remedies for the long and short worm bred in their intestines. The short ones are the creatures here to be described; but though the world has solong been acquainted with their existence, it never knew their origin, till M. Vallisneri discovered, of late, that they were produced from one of these flies, by insinuating itself into the fundament of the horse. These flies always live in the open fields, and are seldom found near towns or houses; and this is the reason that those horses which are kept up in the stable in summer and autumn are scarcely ever found to be so subject to these worms.

IN the latter end of summer, and in autumn; these flies are found continually buzzing about the backs of horses in the open field, secking an opportunity to deposit their eggs. Horses, at this scason, are sensible of the businefs of this little annoyer, and have been seen, from the most quiet state, to jump, run about, and kick, only at the. sound of the wings of one of these flies. This insect has been observed, when it bas not succeeded in its first attempt, to fly with lefs noise towards a 
single horse in another part of the field, slity to creep under his tail, and to use some gentle titilation, in order to make the creature open his fundament; and, when a little open, has rentured to creep in, where she finds herself in a proper place for the depositing her eggs. $\Lambda$ fter this the horse has kicked and capered, as if mad, and continued so for upwards of a quarter of an hour.

THE worms hatched from these eggs soon fink their way farther up the intestines, and often pe. netrate into the stomach. After a sufficient time for acquiring their destined growth, they naturally quit the stomach, in order to get towards the lower part of the intestines, and are either voided with the dung, or of themselves crawl out.

THERE is nothing singular in the figure of these worms. They are larger than those of the common flesh-fly, and smaller than those of the ox-fly: they are somewhat of a conic figure, their heads being pointed, and their posterior part mucls larger ; they are each provided with two crusta'ceous hooks, by which they lay hold, and pull themselves along, by that means, asd adhere so firmly to the coats of the intestines, as to prevent their being forced out of their habitation by the fœces, before they are ripe for their chrysalis state. 
WHEN these worms are only in small numbers in a horse, they do very little harm to the animal; but there are seasons in which they increase to such vast numbers, that they become a very fatal inalady. In some years, when horses have died of a sort of epidemical disease, after they have been opened, prodigious quantities of these worms have been found living in their stomachs, each having formed a sort of cell in its membranes, and all being lodged there, as close together as the seeds in a pomegranate. Nor need we wonder how such immense numbers should be found in one horse, since one female is able to deposit several hundreds.

WHEN these worms are fallen from the intestines; they crawl about till they find some place of safety, where they make a shell of their skin, and undergo all their changeses; whence they finally come out in the form of their parent fly.

From what has been said, it may be suspected, that all horses which have been at grafs during the summer and autumn, have received a quantity of these worms into their intestines; and that it becomes evidently necefsary that a course of physic should be adopted, on their being removed. into a stable. For the destruction and removal of 
xhese wolms, the following medicine will be found most effectual :

Take yeliow emetic mercury, one dram; liquorice, and linseed poivder, of each half an ounce; syrup or honey sufficient to form the mafs; and divide into two balls.

THe horse should be put upon a diet of bran mashes before this medicine is given; after which let him take one of these balls, and the other about forty hours afterwards. And when you have waited about the same time for the operation of the medicine, let the following brisk purge be given :

Take Barbadoes aloes, from six to eight drams; calomel, one dram; Venice turpentine sufficient to form the ball.

By paying proper attention to the operation of the above medicines, we may be able to judge if it has the desired effect; but if, after it is over, we suspect that there are still some worms remaining, a second course may be repeated in about a fortnight afterwards.

DURING the taking of the above medicine, the 
horse should be iiept warmly clothed, and his dict mashes, with gentle exercise.

IF the horse is affected with common worms, the above course of physic will be found equally efficacious for their destruction.

\section{Diseases of the Eyes.}

IN speaking of the eyes, we shall only take notice of those diseases which it is in our power to remorc; as we consider that a description of those which are incurable must not only be tedious, but also uselefs to the reader.

As there is scarcely any accident to which the horse is incident, which takes so much from his ralue as the lofs of one or both eyes; so we shall endeavour, after pointing out the cause and effect, to lay down such methods of cure as we have ever found most advantageous.

WHEIT the cye of the horse becones injured by a violent blow, bite, \&c. we first perceive the eyelids become inflamed, and often lymph is extravasated into the anterior chamber, or fore-part of the eyc; soon after the vesels of the cornea, or Dister part of the glowe of the eye, become ob- 
structed, and it loses its natural transparency. This is what is commonly calied specks or film, which obstructs the sight, and sometimes produces total blindnefs.

WVE often find this complicated disease very difficult to remove; for if we apply stimulants to remove the obstruction, by promoting absorption, which is the only method of curing the eye, we often increase the inflammation of the eye-lids to a great degree; and if sedatives be used to remore the inflammation of the eye-lids, we are in imminent danger of making the obstruction permanent, by lefsening the action of the small velsels, and the obstructed matter, by that means, becoming fixed.

THE following method, in this complicated case, we have often found to answer every intention of cure:

LET two quarts of blood be immediately taken away; then let a gentle dose of physic be given, and let the eye, and parts about it, be fomented six or eight times a day, for three or four days, with warm water. This will in a great degree remove the inflammation of the eye-lids; after which let the following stimulating mixture 
be injected with a syringe gently into the eyc, three times a day:

Take white vitriol in powder, one scruple; rose or common rain water, eight ounces; tincture of opium, sixty drops : mix them together for use.

IT sometimes happens, that a more powerful stimulant is required; for which purpose, a little common salt, very finely powdered, and thrown into the eye once a day, will have an excellent effect. A diuretic ball may be given every day, for a week, and the fomentations of warm water continued.

If the eye-lids are only inflamed, it may arise fiom cold; and there is a discharge of tears, which sometimes becomes acrid. Sugar of lead, in the proportion of one dram to a pint of rain water, is the best application for this complaint, with occasional bleeding, and diet of opening mashes.

The eye of the horse is likewise subject to cataract, or opacity of the crystaline lens, and to gutta serena, or palsy of the optic nerve. The latter may be discovered by the eye losing the power of dilating, or contracting its pupil : this is 
incurable. The cataract, if in its incipient stage, may sometimes be relieved by a long-continued application of stimulant medicines.

IT sometimes happens, if the eye has been much injured, tisat specks remain on the cornea; and if they have been of long continuance, are very difficult to remove: absorption in these small vefsels taking place but slowly, all the hopes of removal depends on a long-continued application of such stimulants as have been recommended, assisted occasionally with diuretics and gentle exercise.

THERE is another disease which sometimes affects the eyes of the horse, which seems to be constitutional, known by the appellation of Moon Blindnefs. This is discovered by our finding one of the eyes in a high state of inflammation, without any apparent cause: this in a few weeks returns to its natural state, and we soon find the other eye affected in the same manner, this keeps going on alternately, and "generally ends in total blindnefs. All the hopes we have of cure in this case, are from often-repeated fomentations of warm water, occasional bleeding, and a course of mild alteratives, \&c. 
If the external parts of the eye are wounded, the wound must be treated in the same manner as directed under the article Wounds.

\section{Of the Membrane Nictatans.}

NATURE, in forming the eye of the horse, seems to have been aware of the many accidents to which it would be liable, and has providentially provided for its security, by the addition of a muscie to draw it back into the socket, and by having furnished it with a cartilaginous substance at its inner canthus, which he can at pleasure, or when apprehensive of danger, thrust out, so as nearly to cover the whole of the eye.

THis substance is commonly called the Haw; and, until very lately, has been considered as a preternatural enlargement, which has been attributed to different diseases; and, of course, has been by most authors directed to be difsected away, to the evident injury, if not total iofs of the eye, and by that means destroying one of the best harriers which Nature had formed for its preservation. 


\section{On Roaring.}

THIS is a disease not noticed by any writer we have seen, and takes its name from the noise the horse makes in breathing, when put into a brisk motion. This noise is owing to lymph being extravasated, and coagulating on the inside of the trachea, or windpipe, and by that means obstructing respiration.

THE principal cause is sudden, or long continued violent exercise.

IN its incipient stage, blistering the whole length of the wind-pipe may be of use; but when the disease has continued a length of time, it be. comes incurable.

\section{Broken Knees.}

AMONGST the number of accidents to which the horse is liable, there is none more frequent than those which come under the denomination of Broken Knees, which very frequently leaves a blemish that is never effaced. This is often owing to an error of treatment.

WHEN the horse unfortunately meets with this 
accident, the best method of practice is, to wasis the parts which have been injured with warm water, to remove any extraneous matter; then let them be bathed with French brandy frequently for the first two or three days, and let the following ointment be applied over the wound with the hand, which will, by its gentle stimulating power, brace the parts, promote the cure, and facilitate the growth of hair :

Take cantharides in fine powder, one dram; olive oil, one ounce; mix, and apply occasionally.

\section{Mallender's and Sallenders}

ARE so generally known, as to render a description uselefs. We shall only subjoin a prescription, which, if well rubbed on the parts affected, seldom fails to remove them at once or twice drefsing.

Take strong mercurial ointment, one ounce; sublimate in fine powder, ten grains: $\mathrm{mix}$ them well in a marble mortar for use. 


\section{On Depraved Appetite.}

IT is observed, that horses returning from grafs, but particularly at camp, have frequently depraved appetites, which shows itself by their fondnefs for sand, earth, or litter. If this appetite is permitted to be much indulged, large balls are somętimes formed in the intestines, which frequently obstruct the parsage of the foces to such a degree as to occasion death. When this depraved appetite is observed, it will be best to give the horse repeated small doses of laxative medicines.

\section{The Distemper.}

IN England, horses are extremely subject to receive injury from the sudden changes which take place in the temperature of the atmosphere, particularly during the spring and autumn quarters; the moisture of the air at these periods, combined with the heat, is very apt to produce inflammation of the mucous membranes, coughs, and sometimes inflammation of the lungs. When this inflammation and courgh is attended with a discharge of matter from the nostrils, it constitutes a disease which is called the Distemper, for which every farrier thinks that he has an infallible antidote; but 
it is frequently found, that a number of valuable horses fall victims to this disease; which we conceive may be owing to the error of treatment.

THE principal symptoms observable in the distemper are, first, a slight inflammation of the top of the throat, attended with a cough, which becomes more frequent and violent, particularly when the patient attempts to swallow his food; the action of the heart and arteries are increased, and the pulse is more quick and hard, with some degree of fever; the tongue is very hot and white, but not always dry, being sometimes covered with tough mucus; and when difficulty of breathing is joined to these symptoms, we have great reason to appiehend that the lungs are affected.

THERE is very little appearance of any enlargement of the external glands about the neck, or under the jaw, as in strangles, the inflammation being principally confined to the throat, windpipe, and adjacent parts, which appear much tumified and sore.

WHERE no medicines have been given, or any operation used, this disease terminates by a critical purging, but more frequently by a large secretion 
of matter from the nostrils. The method of practice we have found most effectual for the cure of the distemper is as follows :

Frequent bleeding in small quantities, about three pints at a time, and a hair bag, containing a large mash, nearly scalding hot, should be fastened on the head and round the nostrils, so as the patient may inhale the whole of the hot steam; and the mash should be changed four or five times a day. This will relax the inflammation of the throat, and promote a more free discharge of matter from the nostrils.

If there be much fever, which is generally the case, half an ounce of nitre, difsolved in two quarts of water in which bran has been steeped, may be given, a little warm, at one time, or used as his ordinary drink. And if there be any difficulty in his breathing, the bleeding may be increased to three or four quarts the first time, and afterwards in small quantities, or as symptoms may direct.

The horse should be moderately warm clothed, and should frequently be gently exercised; and if oats are given, they should be bruised, and steeped in hot water. 
In the place of hay, fresh grafs, where it cara be procured, will be found the best diet, as it has a tendency to keep the body cool, and gently open the intestines. 


\section{A P P E D I X: OR,}

VETERINARY DISPENSATORY, CONTAINING

The most approved Prescriptions TOR THE DIFEERENT DISEASES OF THE HORSE. 



\section{A P P E N D I}

\section{No 1. \\ Nild purging Ball.}

- Take Barbadoes aloes in fine powder, six drams; ginger in powder, one scruple; - $\quad$ soft soap sufficient to form the ball.

THIs ball gently purges and cleanseth the inrestines, without causing the least griping pain, and may be usefuly employed when horses return from grafs, or where gentle purging is required. Two or three drams of aloes added to the above ball, makes the strong purging ball.

\section{No 2.}

\section{Mercurial purging Ball.}

Take Barbadoes aloes in fine powder, four drams; calomel, one dram; ginger in powder, one scruple: mucilage of gum arabic sufficient to form the ball.

THis ball may be made stronger, if required, by the addition of half a dram to one dram of calomel, and will prove exccllent where worms pre susspected. 


\section{No 3.}

Diuretic, or Urine Balls.

Take yellow resin, Castile soap, Venice tur pentine, of each one pound; difsolve them them together over a slow fire; and, when sufficiently incorporated, set them aside to cool, and form balls.

HALF an ounce to one ounce and a half of the above may be given where urine balls are required; the common dose is one ounce. These balls are excellent diuretics, and may be given in gripes, swelled legs, grease, or in diseas es of the eyes, \&c.

No 4.

Stomachic Balls.

Take Peruvian bark in fine powder, eight ounces; grains of paradise in fine powder, two ounces; gentian in powder, Columba root in powder, of each three ounces; honey sufficient to form the whole sixteen of a proper consistency, and divide into sixteen balls.

$\mathrm{ONE}_{\mathrm{N}}$ of these balls may be given every morning, and will be found excellent for indigestion and lofs of appetite. 


\section{No 5.}

\section{Improved Cordial Balls.}

Take grains of paradise in fine powder, two ounces; ginger in powder, winter bark in powder, of each half an ounce; anniseseeds, caraway-seeds in powder, of each an ounce and a half; liquorice in powder, two ounces; honey sufficient to form eight balls.

WHERE cordial balls are required, one of these may be given occasionally.

$$
\text { No6, }
$$

Mild Camphor, or Fever Balls.

Take camphor, one dram and a half; nitre, cream of tartar, of each three ounces; mucilage of gum-arabir sufficient to make the pall.

THis ball will be found excellent, given in the n̂irsi attack of fever. 


\section{No 7. \\ Fever Powder.}

Take antimonial powder, ten grains; nitre, cream of tartar, of each half an ounce: mix them for use.

This powder is excellent in inflammation of the lungs, or continued fever, given every two hours, in one quart of strong linseed tea.

\section{No 8.}

IIIld alterative Powders for promoting Condition.

Take common antimony in fine powder, one pound; nitre, twelve ounces: mix them together for use.

ONE cunce of this powder may be given every night and morning in the horse's corn, previously sprinkled with water, to make it adhere, or made into a ball with a little tar; and will be found very useful in promoting condition, or removing any long-continued coughs, colds, or discharge of matter from the nostrils. 


\section{No 9.}

Mild Drink for Pains of the Bowels, Looseness, or Difficulty in Staling.

Take gum-arabic in powder two ounces ; dissolve it in three quarts of boiling water; when cold, add tincture of opium, half an ounce, and mix them well together.

THIs mixture may be given every six hours, in violent loosenefs, pains of the intestines, or where there is great difficulty in staling.

$$
\text { No } 10 .
$$

Eye-Water, for Film or Specks.

Take white vitriol purified, two drams; rose water, one pint; tincture of opium, three drams: mix them well together.

THIs tincture may be applied to the eye three rimes a day, with a feather or syringe, until the disease is remored.

\section{No 11.}

Mixture for Strains, Swellings, \&C.

Take sugar of lead, half an ounce; best vinegar, one pint; rectified spirits of wine, four ounces : mix them well together.

A bandage may be kept round the strained part, and kept constantly moist with this mixture. 


\section{No 12.}

\section{Mixture for old Sores.}

Take spirits ammoniæ compound, three ounces; soccotrine aloes in fine powder, one dram; aquafortis, two drams: mix them in an open vefsel. After the aloes is difsolved, keep it in a bottle, close stopped, for use.

THIs mixture will be found very useful in old sores or ulcers.

$$
\text { No } 13 .
$$

\section{Blister Ointment.}

Take cantharides in fine powder, one ounce; ointment of yellow resin, purified hog's lard, of each two ounces: mix them well together for use.

THIs is an excellent blister, and never destroys the roots of the hair, and never leaves any blemish on the part to which it has been applied.

\section{No 14.}

Strong Blister Dintment for Bone Sparin, Splints, $\mathbb{S}_{\boldsymbol{C}}$.

Take sublimate mercury in fine powder, two drams; purified hog's lard, three ounces: mix them well together for use. 
No 15.

Digestive Ointment for common Sores.

Take yellow resin, bees wax, Venice turpentine, of each half a pound; difsolve them over a slow fire, constantly stirring them, until they are completely united : set them aside to cool.

\section{No 16.}

Powder for removing Fungus, or Proud Flesh.

Take blue vitriol, one ounce; common alum, three ounces : beat them together in a mortar to a very fine powder, for use.

\section{$\mathrm{N}^{0} 17$.}

Ointment for Mange.

Take purified hog's lard, one pound; sulphur four ounces; hellebore powder, one ounce and a half : mix them well together to form an ointment.

THis ointment must be well rubbed on the parts which are affected with the mange, by the hand, and seldom fails to cure the disease in two or three applications. 


\section{No 18.}

\section{Common Clyster.}

Take Barbadoes aloes in fine powder, one : ounce ; difsolve it in four quarts of linseed decoction.

THIs, shighily warm, is to be thrown up the rectum with a bladder and pipe: it in general answers any intention of stimulating clysters.

\section{No 19.}

\section{Linseed Decoction.}

Take linseed, half a pound; boil it in five quarts of water, until it is reduced to four quarts : strain it through a coarse cloth for use.

THIs decoction will be found excellent where a mild lubricating clyster is required.

\section{No 20.}

\section{Opodeldoc.}

Take Castile soap, three ounces; camphor, one ounce; spirits of rosemary, one pint: difsolve the soap in the spirits with a very gentle heat; then add the camphor in powder, when it is completely difsolved: keep it in a bottle, close stopped, for use. 


\section{$N^{\circ} 2$. \\ Volatile Opodeldoc.}

Take Castile soap, two ounces; compound spirits of ammonix, one pint; camphor, one ounce; dissolve the soap and camphor in the spirits, with a gentle heat, and keep them for use in a bottle closely stopped.

Botr these liniments will be found excellent in recent strains, bruises, or tumours, on any part of the body. The method of application is, by rubbing a necessary quantity well on the part, with the hand, two or three times a day.

THE END.

1. Gillet, Printer, Salisbury-Square, Fleet-Street. 

$\sqrt{2}$

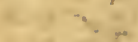

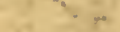
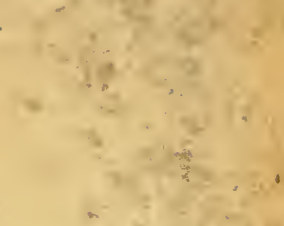

-
4
0

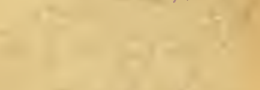

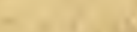
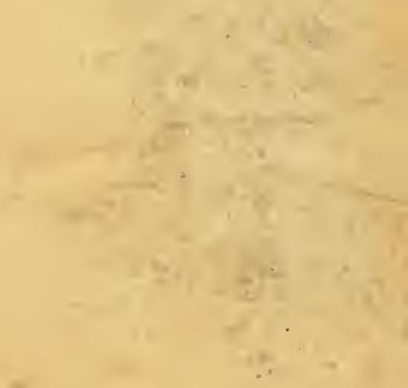

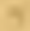

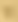

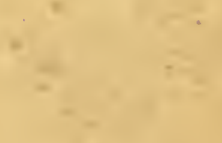

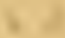


Webster Family Library of Veterinary Medicine Cummings School of Veterinary Medicine at Tufts University 



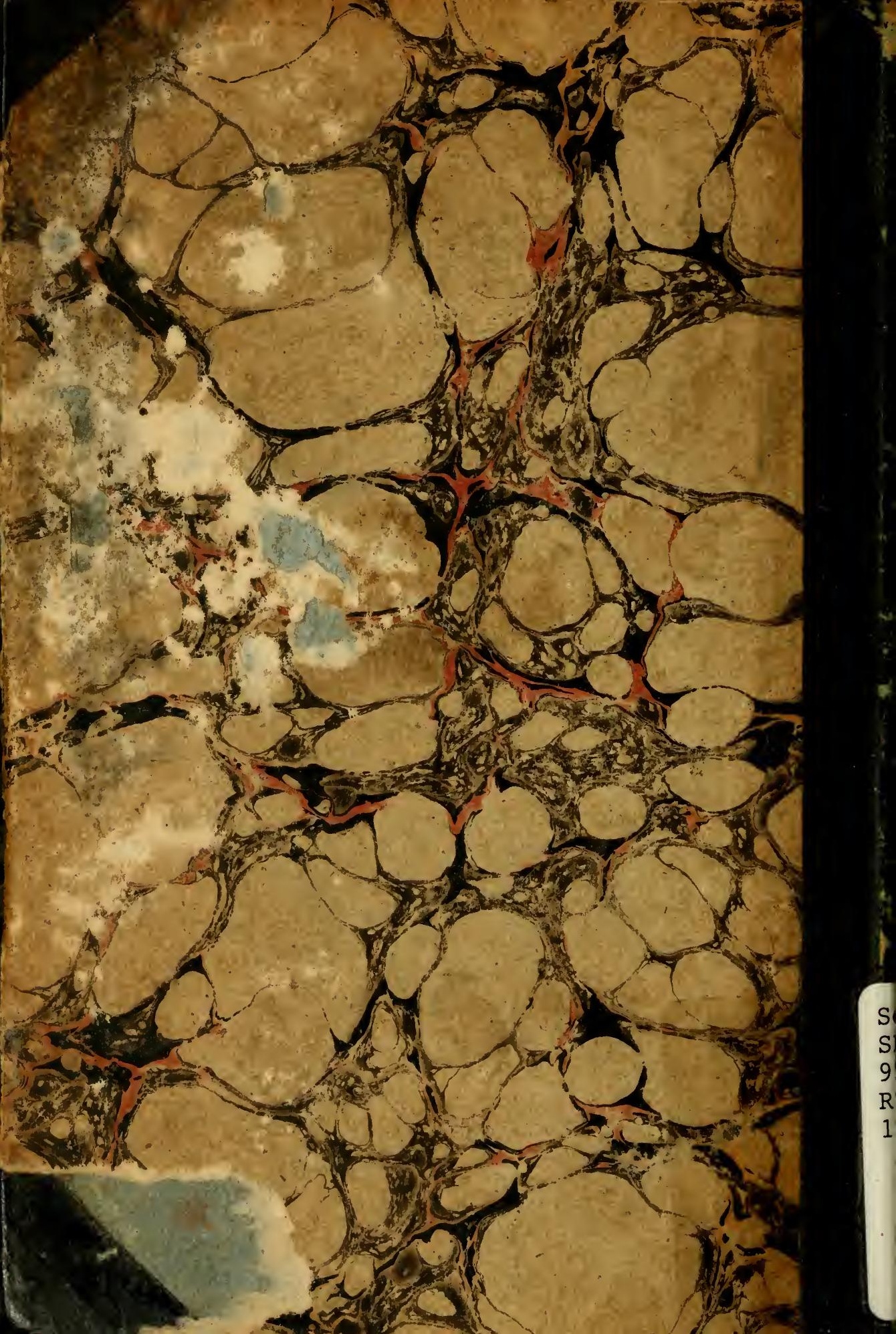

